\title{
Elucidation of the inhibitory activity of plant-derived SARS-CoV inhibitors and their potential as SARS- CoV-2 inhibitors
}

Martiniano Bello ( $\sim$ bellomartini@gmail.com )

Instituto Politécnico Nacional https://orcid.org/0000-0002-9686-0755

Md. Kamrul Hasan

National University, Gazipur, Bangladesh

\section{Research Article}

Keywords: COVID-19, SARS-CoV-2 3CLpro, binding free energy, Molecular docking, Molecular dynamics simulation

Posted Date: April 13th, 2021

DOI: https://doi.org/10.21203/rs.3.rs-383586/v1

License: (c) (i) This work is licensed under a Creative Commons Attribution 4.0 International License.

Read Full License 


\section{Abstract}

Due to the necessity of treating the SARS-CoV-2 infection, several drugs are now being tested as possible therapies. Although approved vaccines bring much hope, a vaccination program covering the entire global population will take a very long period, which makes the development of effective antiviral drugs an effective solution for the immediate treatment of this dangerous infection. Previous studies found that three natural compounds: tannic acid, 3-isotheaflavin-3-gallate and theaflavin-3,3-digallate are effective proteinase (3CL $\left.{ }^{\text {pro }}\right)$ inhibitors of $S A R S-\operatorname{CoV}\left(\mathrm{IC}_{50}<10 \mu \mathrm{M}\right)$. Based on this information, and due to the high percentage of sequence identity of SARS-CoV and SARS-CoV-2 $3 \mathrm{CL}^{\text {pro }}$, these three compounds could be candidate inhibitors of SARS-CoV-2 $3 \mathrm{CL}^{\text {pro }}$. In this paper, we explore the structural and energetic features that guided the molecular recognition of these three compounds for dimeric SARS-CoV2 and SARS-CoV $3 \mathrm{CL}^{\text {pro }}$, the functional state of this enzyme, by using docking and MD simulations with the molecular mechanics-generalized-born surface area (MMGBSA) approach. Energetic analysis demonstrated that the three compounds reached favorable affinities in both systems in the following order: tannic acid $>3-$ isotheaflavin-3-gallate > theaflavin-3,3-digallate, a tendency that is in line with that which was experimentally reported between these ligands and SARS-CoV 3CL ${ }^{\text {pro }}$. Therefore, tannic acid may have clinical usefulness against COVID-19 by acting as a potent inhibitor of SARS-CoV-2 $3 \mathrm{CL}^{\text {pro }}$.

\section{Introduction}

Severe acute respiratory syndrome coronavirus 2 (SARS-CoV-2), the 7th coronavirus species to be discovered that infects humans, is the causative agent of the ongoing COVID-19 viral pandemic [1-3]. The virus was first discovered in Wuhan in late 2019, causing a pneumonia-like outbreak that quickly spread throughout the globe [4]. In March 2020, the World Health Organization (WHO) declared SARSCoV-2 as a pandemic due to its extreme outbreak [5], and notified the global authorities to take emergency measures including travel bans to stop the viral propagation; since then, 7 months have passed, yet the spread of the virus is barely slowing. While many countries have successfully combated the pandemic and have been declared SARS-CoV-2 free, the pandemic situation has relapsed in several others. So far, approximately 2.1 million lives have been lost globally to COVID-19, with 98.3 million people still infected [https://www.worldometers.info/coronavirus/]; the global COVID-19 situation seems hardly optimistic overall. While the virus was initially reported to cause fever, coughing, sneezing and breathing difficulties in non-critical cases, and pneumonia and multiple organ failure leading to death in severe cases [1], recent studies indicate the possibility of the viral infection also causing kidney dysfunction and myocardial injury [6-8]. While SARS-CoV-2 is the third coronavirus epidemic after 2002 SARS and 2012 MARS [3], it is by far the deadliest of the three and the only one to spread on a global scale in such a short period of time [9-10].

SARS-CoV-2 is an enveloped, positive-sense, single-stranded RNA virus of the Betacoronavirus order under the Coronaviridae family, which belongs to the Nidovirales order. It has been suggested that SARSCoV-2 followed a similar evolutionary transmission cascade to SARS-CoV and MERS-CoV, both of which 
have zoonotic origins, with their natural originator being bats [6,11-12]. It has also been confirmed that SARS-CoV-2 shares $\sim 80 \%$ sequence identity with SARS-CoV [13]. While most coronaviruses generally contain 6 open reading frames (ORFs), SARS $\operatorname{CoV}-2$ contains 14 , among which ORF $1 \mathrm{a} / \mathrm{b}$ plays the most substantial role in viral proliferation [14-16]. ORF $1 \mathrm{a} / \mathrm{b}$ translates into two overlapping polyproteins, pp1a and pp1ab, which are cleaved by the main protease $3 \mathrm{CL}^{\text {pro }}$ and the papain-like protease $\mathrm{PL}^{\text {pro }}$ enzymes into 16 non-structural proteins, including a major protein for viral reproduction such as the $\operatorname{RdRp}[14,15$, 16-19]. It has been discovered that the $\mathrm{PL}^{\text {pro }}$ enzyme also recognizes the $\mathrm{C}$-terminal sequence of ubiquitin [20], but the $3 \mathrm{CL}^{\text {pro }}$ enzyme exclusively cleaves polypeptide sequences after a glutamine residue [21]. The rest of the genome sequence translates into structural proteins which include the spike glycoprotein (S), an envelope protein (E), the membrane protein $(M)$, and the nucleocapsid phosphoprotein $(\mathrm{N})$. The spike glycoprotein $(\mathrm{S})$ recognizes the human angiotensin-converting enzyme-2 (ACE-2) receptor, which makes it indispensable for viral propagation $[15,22]$.

Since the discovery of SARS-CoV-2 in late 2019 , scientists have developed various methods to alleviate the severity of the disease and minimize the spread of the infection; after the declaration of a pandemic by WHO, it elevated to a global effort for the rapid development of vaccines and specific anti-viral treatments. While the Oxford vaccine development being in phase 3 trials [23] brings much hope, its accreditation as an effective vaccine is still not fully certain; besides that, the implementation of a vaccination program covering the entire global population will take an extremely long time, which makes the development of effective antiviral drugs an effective solution for the immediate treatment of this lifethreatening infection.

Scientists have vested much effort in developing new antiviral drugs with a substantial group of researchers focusing on drug repurposing, as this method is faster than developing novel medicines. Among the anti-viral drug targets that have been studied against coronaviruses, the $3 \mathrm{CL}^{\text {pro }}, \mathrm{PL}^{\text {pro }}, \mathrm{RdRp}$, and spike glycoprotein (S) have been treated as major drug targets for the anti-viral treatment of diseases as they play crucial roles in viral proliferation and infections [21,24-25]. The deubiquitinase nature of $\mathrm{PL}^{\text {pro }}$ makes substrate-derived inhibitors of $\mathrm{PL}^{\text {pro }}$ also inhibit host-cell deubiquitinases, making drug development targeting PL ${ }^{\text {pro }}$ arduous [20]. Several FDA-approved RdRP inhibitor drugs, including Remdesivir, Favipiravir, Sofosbuvir, Ribavirin, Lopinavir, Ritonavir, Tenofovir, and Galidesivir, have been shown to be effective against a broad range of RNA viruses, including past coronaviruses, and have been tested against SARS-CoV-2 for potential anti-viral treatment. So far, only Remdesivir showed a reduction in the recovery period; however, it had zero impact on mortality [6, 26-29]. A recent computational study opted for an alternate pathway by using structural analogs of FDA-approved RdRP inhibitor drugs; while the result of this analysis was shown to be optimistic, the computational nature of the study makes the possibility of developing effective anti-viral drugs uncertain [30]. The $3 \mathrm{CL}^{\text {pro }}$ of SARS-CoV-2 proteolytically cleaves the pp $1 \mathrm{a}$ and $\mathrm{pp} 1 \mathrm{ab}$ polyproteins from ORF a/b into functional proteins, a critical step during viral replication, representing an important target for dropping the impact of COVID-19 [21]. The alignment of $3 \mathrm{CL}$ pro of SARS-CoV-2 and $3 \mathrm{CL}^{\text {pro }}$ of SARS-CoV showed that these proteins share up to $95 \%$ sequence identity, indicating that SARS-CoV $3 \mathrm{CL}^{\text {pro }}$ inhibitors may function in a similar way against 
SARS-CoV-2. In fact, different theoretical studies repurposed from $3 \mathrm{CL}^{\text {pro }}$ of SARS-CoV have been published to identify new inhibitors of monomeric $[6,31,32]$ and dimeric $3 \mathrm{CL}^{\text {pro }}$ of SARS-CoV-2 $[33,34]$, with the latter being the conformation of the active enzyme [34]. Using this to the advantage, herein this study naturally available three plant-derived SARS-CoV $3 \mathrm{CL}^{\text {pro }}$ inhibitors: Tannic acid, 3-isotheaflavin-3gallate and theaflavin-3,3-digallate compounds, which have been confirmed to have potent SARS-CoV

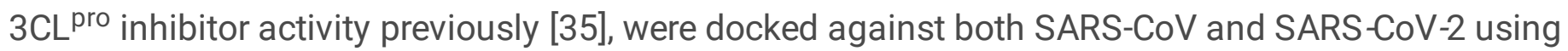
molecular docking analysis, protein-ligand interactions, molecular dynamic simulations, and free energy calculation, to predict their potential for antiviral treatment of SARS-CoV-2 using nutraceuticals.

\section{Methods}

\subsection{Preparation of Systems}

Tannic acid (TA), theaflavin-3,3-digallate (TF3) and 3-isotheaflavin-3-gallate compounds were obtained from ChemSpider (http://www.chemspider.com/), and optimized at the AM1 level with Gaussian 09W software [36]. The X-ray crystallography structures of SARS-CoV-2 3CL ${ }^{\text {pro }}$ (PDB ID: 6LU7, 2.16 $\AA$ ) and SARS-CoV 3CL ${ }^{\text {pro }}$ (PDB ID: 2GX4, $1.93 \AA$ ) were employed to construct the protein-ligand complexes.

\subsection{Molecular docking}

The three compounds were docked on dimeric SARS-CoV2 $3 \mathrm{CL}^{\text {pro }}$ and SARS-CoV $3 \mathrm{CL}^{\text {pro }}$ using AutoDock Tools 1.5.6 and AutoDock 4.2 programs [37]. Hydrogen atoms were added to the ligands and protein atoms, and Kollman and Gasteiger partial charges were given for the receptor and ligand, correspondingly. The grid box was placed on the binding site of each monomeric subunit of dimeric SARS-CoV-2 $3 \mathrm{CL}^{\text {pro }}$ and SARS-CoV $3 \mathrm{CL}^{\text {pro }}$ with grid xyz points of $70 \times 70 \times 70 \AA$, respectively, and a grid space of $0.375 \AA$. Ligand location was assessed using a Lamarckian-genetic algorithm. The proteinligand complex with the lowest binding free energy was designated as the initial conformer to start MD simulations. The docking was validated by replicating the binding mode of inhibitor N3 and TG-0205221 on SARS-CoV-2 3CL ${ }^{\text {pro }}$ SARS-CoV2 Mpro (PDB ID: 6LU7) and SARS-CoV 3CL ${ }^{\text {pro }}$ (PDB ID: 2GX4) with RMSD values lower than $1.0 \AA$.

\subsection{MD simulations}

MD simulations were performed with AMBER16 software [38] using the ff14SB force field [39]. The force field of the three compounds was done using AM1-BCC atomic charges and the general Amber force field (GAFF) [40]. Each system obtained through docking was neutralized with $0.10 \mathrm{M} \mathrm{NaCl}$ and then solvated in a dodecadic box of $12.0 \AA$ using the TIP3P water model [41]. Minimization and the equilibration of solvated and neutralized systems consisted of the following steps: minimization through 1000 steps using the steepest descent method, and 3000 steps using the conjugate gradient method. Afterward, the systems were heated through 200 ps, and then the density was equilibrated through 200 ps; finally, the systems were equilibrated with 600 ps of constant pressure equilibration at $310 \mathrm{~K}$. MD simulations were 
run for $100 \mathrm{~ns}$ with triplicate experiments under an NPT ensemble at $310 \mathrm{~K}$. The electrostatic forces were described by the PME method [42], and a $10 \AA$ cutoff was selected for the van der Waals interactions. The SHAKE algorithm [43] was employed to constrain bond lengths at their equilibrium values. Temperature and pressure were preserved using the weak-coupling algorithm [44]. The MD results were analyzed using AmberTools16, whereas that images were built using Maestro Schrödinger version 10.5 [45].

\subsection{Binding free energy and per-residue decomposition calculations}

The MMGBSA $[46,47]$ approach was used to determine the binding free energy $\left(\Delta G_{\text {bind }}\right)$ values for the complexes and to determine the per-residue decomposition energy. Five hundred snapshots at time intervals of $100 \mathrm{ps}$ were taken over the equilibrated time (over the last $70 \mathrm{~ns}$ ). Prior to the analysis, all counter-ions and water molecules were removed, and a salt concentration of $0.10 \mathrm{M}$ was considered with the implicit solvation model [48]. $\Delta G_{\text {bind }}$ and per-residue decomposition analysis were calculated as described elsewhere [49], and the $\Delta G_{\text {bind }}$ values signify the average values of three experiments.

\section{Results And Discussion}

\subsection{Docking results}

\subsubsection{Docking interactions between TA with $3 \mathrm{CL}^{\text {pro }}$ of SARS-CoV-2 and SARS-CoV}

The tannic acid (TA) docked complex with the $3 \mathrm{CL}^{\text {pro }}$ of SARS-CoV-2 was shown to have a total of $11 \mathrm{H}-$ bonds in 8 residues of subunit 1 (Figure 1A, supplementary material); these 4 residues were similar to the

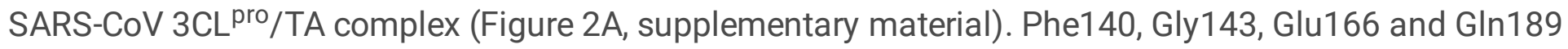
of subunit 1 via H-bond interactions of Glu166 differed between the SARS-CoV 3CL ${ }^{\text {pro }} / T A$ complex and SARS-CoV-2 3CL ${ }^{\text {pro }}$ TA complex as Glu166 had a total of $5 \mathrm{H}$-bond interactions with TA in the SARS-CoV $3 \mathrm{CL}^{\text {pro }} / \mathrm{TA}$ complex, whereas $3 \mathrm{H}$-bonds were formed in the SARS-CoV-2 3CL ${ }^{\text {pro }} / \mathrm{TA}$ complex. Also, both complexes had a common $\mathrm{H}$-bond interaction with residue 46, though in the SARS-CoV-2 3CL ${ }^{\text {pro }} / T A$ complex, it was changed to a Ser residue which was Ala 46 in the SARS-CoV $3 \mathrm{CL}^{\text {pro }} / \mathrm{TA}$ complex.

In the case of subunit 2 of the SARS-CoV-2 3CL ${ }^{\text {pro }} / T A$ complex (Figure 1B, supplementary material), a total of $11 \mathrm{H}$-were formed by 9 residues; among these, 2 residues were similar to the SARS-CoV $3 \mathrm{CL}^{\text {pro }} / \mathrm{TA}$ complex (Figure 2B, supplementary material). Ser139 and $\mathrm{G} \ln 189$, through $\mathrm{H}$-bond interactions with GIn189, differed between the SARS-CoV 3CL ${ }^{\text {pro }} / T A$ complex and the SARS-CoV-2 3CL ${ }^{\text {pro } / T A ~ c o m p l e x ~}$ as GIn189 had a total of $2 \mathrm{H}$-bond interactions with TA in the SARS-CoV-2 3CL ${ }^{\text {pro }} / \mathrm{TA}$ complex whereas only one H-bond was formed in the SARS-CoV 3CL pro/TA complex. Subunit 1 of the SARS-CoV-2 $3 \mathrm{CL}^{\text {pro}} / \mathrm{TA}$ complex had a total of 16 polar contacts with TA and 11 of these contacts held similar positions in the SARS-CoV 3CL pro/TA complex with residues Thr25, Ser144, His163, His164, His172, Gln189, Thr190 and Gln192 of chain A and Ser1, Asn214 and GIn299 of chain B. Subunit 2 of the SARSCoV-2 3CL ${ }^{\text {pro }} / \mathrm{TA}$ complex also had a total of 16 polar contacts with TA; among these, 8 residues 
including Asn214 in chain A and Thr25, His41, Ser139, Asn142, Ser144, Gln189 and Gln192 of chain B were found to be common, and both complexes also had a common polar residue, no. 169 of chain $B$, although in the SARS-CoV-2 3CL pro/TA complex, it was changed to a His residue rather than being Thr169 in the SARS-CoV $3 \mathrm{CL}^{\text {pro }} / \mathrm{TA}$ complex. Analyzing the hydrophobic interactions, subunit 1 of SARS-CoV-2 $3 \mathrm{CL}^{\text {pro}} / \mathrm{TA}$ complex was shown to have a total of 14 hydrophobic contacts with TA; among them, 10 contacts were shown to be similar to the SARS-CoV 3CL pro/TA complex, which includes the Met49, Phe140, Leu141, Cys145, Met165, Leu167, Pro168 and Ala191 residues of chain A and the lle213 and Cys300 residues of chain B. Subunit2 of the SARS-CoV-2 3CL ${ }^{\text {pro }} / T A$ complex formed a total of 22 hydrophobic contacts with TA; among them, 10 contacts were shown to be similar in the SARS-CoV

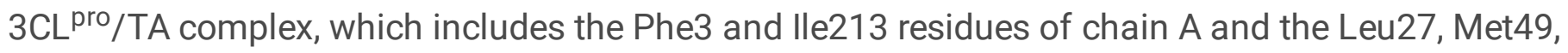
Phe140, Leu141, Cys145, Met165, Leu67 anf Ala191 residues of chain B. From a comparative observation, tannic acid (TA) as a ligand showed a considerable higher binding affinity for the SARS-CoV$23 \mathrm{CL}^{\text {pro }}$ enzyme than for the SARS-CoV $3 \mathrm{CL}^{\text {pro }}$ enzyme.

\subsubsection{Docking interactions between TF3 with $3 \mathrm{CL}^{\text {pro }}$ of SARS-CoV-2 and SARS-CoV}

Subunit 1 of the SARS-CoV-2 3CL ${ }^{\text {pro }}$ complex with theaflavin-3-3-digallate (TF3) displayed $4 \mathrm{H}$-bonds by 3 residues of the subunit 1 (Figure 3A, supplementary material); among these, only 1 residue was similar to the SARS-CoV 3CL ${ }^{\text {pro }} / \mathrm{TF} 3$ complex (Figure 3C, supplementary material), respectively the Glu166 residue of chain A. Although H-bond interactions of Glu166 differed between the SARS-CoV 3CL ${ }^{\text {pro } / ~ T F 3 ~ c o m p l e x ~}$ and the SARS-CoV-2 3CL ${ }^{\text {pro }} / \mathrm{TF} 3$ complex, Glu166 had a total of $3 \mathrm{H}$-bond interactions with TF3 in the SARS-CoV 3CL complex. In subunit 2 of the SARS-CoV-2 3CL pro/TF3 complex, $4 \mathrm{H}$-bond interactions have been observed (Figure 3B, supplementary material) of which only 1 residue, Glu166, was similar to the SARS-CoV 3CL ${ }^{\text {pro }} / \mathrm{TF} 3$ (Figure 3D, supplementary material) complex which had a total of $8 \mathrm{H}$-bonds, although it must be noted that the Glu166 residue of the SARS-CoV 3CL pro/TF3 complex formed $2 \mathrm{H}$-bonds, unlike the residue from the SARS-CoV-2 3CL pro/TF3 complex which only formed $1 \mathrm{H}$-bond. SARS-CoV-2 $3 \mathrm{CL}^{\text {pro }} / \mathrm{TF} 3$ complex subunit 1 formed 9 polar contacts with TF3, of which 7 were common with SARS-

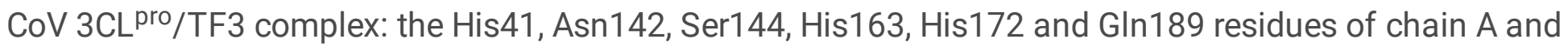
the Ser 1 residue of chain B. On the other hand, subunit 2 formed 11 polar contacts with TF3, of which 7 residues were found to be similar to SARS-CoV 3CL pro/TF3: Thr26, His41, Asn142, Ser144, His163, His172 and GIn189. Subunit 1 of the SARS-CoV-2 3CL pro/TF3 complex formed 7 hydrophobic contacts with TF3, of which 6 residues were common with SARS-CoV 3CL ${ }^{\text {pro }} / \mathrm{TF} 3$ complex subunit 1: Met49, Phe140, Leu141, Cys145, Met165 and Leu167 of chain A. Subunit2 of the SARS-CoV-2 3CL ${ }^{\text {pro/TF3 }}$ complex formed a total of 8 hydrophobic contacts, with 6 residues that were common to SARS-CoV

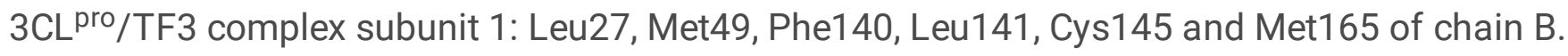

\subsubsection{Docking interactions between TF2B with $3 \mathrm{CL}^{\text {pro }}$ of SARS-CoV-2 and SARS-CoV}




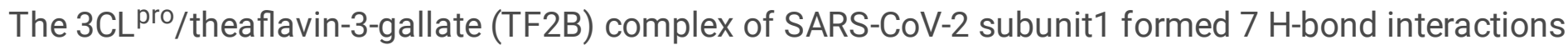
(Figure 4A, supplementary material) between 5 residues of the receptor-ligand; among them, only 1 residue was similar to the SARS-CoV 3CL ${ }^{\text {pro }}$ /TF2B complex (Figure 4C, supplementary material): Glu166 of chain A. However, the H-bond interactions of Glu166 differed between the SARS-CoV 3CL ${ }^{\text {pro }} / T F 2 B$ complex and the SARS-CoV-2 3CL ${ }^{\text {pro }} / \mathrm{TF} 2 \mathrm{~B}$ complex as Glu166 had a total of $2 \mathrm{H}$-bond interactions with

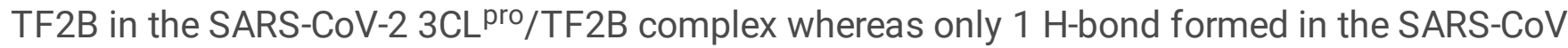

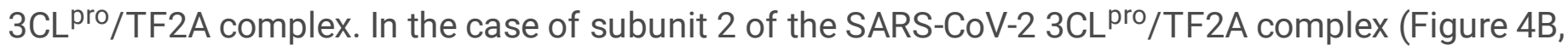
supplementary material), a total of $8 \mathrm{H}$-bonds were formed, among them only 1 residue was similar to the SARS-CoV 3CL ${ }^{\text {pro } / T F 2 A ~ c o m p l e x ~(F i g u r e ~ 4 D, ~ s u p p l e m e n t a r y ~ m a t e r i a l): ~ G l u 166 ~ o f ~ c h a i n ~ B . ~ H-b o n d ~}$ interactions of Glu166 differed between the SARS-CoV 3CL ${ }^{\text {pro }} /$ TF2B complex and the SARS-CoV-2 $3 L^{\text {pro }}$ TF2B complex as Glu166 had a total of $2 \mathrm{H}$-bond interactions with TF2B in the SARS-CoV-2 $3 \mathrm{CL}^{\text {pro }} / \mathrm{TF} 2 \mathrm{~B}$ complex whereas only $1 \mathrm{H}$-bond formed in the SARS-CoV $3 \mathrm{CL}^{\text {pro }} / \mathrm{TF} 2 \mathrm{~B}$ complex. SARS-CoV-

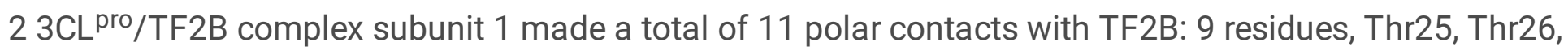
His41, Asn142, Ser144, His163, His172 and Asn189, of chain A and the Ser1 residue of chain B were also present in the SARS-CoV $3 \mathrm{CL}^{\text {pro }} / \mathrm{TF} 2 \mathrm{~A}$ complex; on the other hand, subunit 2 of SARS-CoV-2 3CL ${ }^{\text {pro }} / \mathrm{TF}^{2 B}$ also made a total of 11 polar contacts with TF2B: 6 residues, Thr25, Thr26, His41, Asn142 and Asn189, of chain $B$ were also present in the SARS-CoV $3 \mathrm{CL}^{\text {pro } / T F 2 B ~ c o m p l e x . ~ O b s e r v i n g ~ t h e ~ h y d r o p h o b i c ~}$ interactions, it was found that of the 8 hydrophobic contacts of SARS-CoV-2 3CL pro/TF2B complex subunit 1, 5 were similar to SARS-CoV $3 \mathrm{CL}^{\text {pro } / T F 2 B ~ c o m p l e x ~ s u b u n i t ~} 1$; these residues were Leu27,

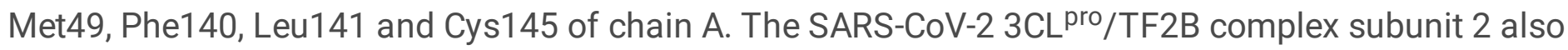
had 8 hydrophobic contacts, with 5 hydrophobic contacts that were similar to SARS-CoV 3CL ${ }^{\text {pro }} / T F 2 A$ complex subunit 2: Leu27, Met49, Leu141, Cys145 and Met165 from chain B. These complexes were further submitted to optimization through MD simulations.

\subsection{MD simulations}

\subsubsection{Convergence of MD simulations}

Root means squared deviation (RMSD) and radius of gyration (Rg) analysis showed that bound SARSCoV-2 $3 \mathrm{CL}^{\text {pro }}$ and SARS-CoV $3 \mathrm{CL}^{\text {pro }}$ reached equilibrium between 10 and $30 \mathrm{~ns}$ with average values that oscillated between $1.8 \pm 0.2$ and $2.8 \pm 0.2 \AA$ for RMSD and $25.8 \pm 0.01$ and $26.1 \pm 0.06 \AA$ for $\mathrm{R}_{\mathrm{G}}$ (Table 1, supplementary material). Therefore, the first $30 \mathrm{~ns}$ were removed from the $100 \mathrm{~ns}$ simulation for further analysis.

\subsubsection{Interactions between TA with 3CL ${ }^{\text {pro }}$ of SARS-CoV-2 and SARS-CoV}

The tannic acid (TA) complex with the $3 \mathrm{CL}^{\text {pro }}$ of SARS-CoV-2 was shown to have a total of $17 \mathrm{H}$-bonds in the subunit (Figure 1), three of which were side chains and the rest were $\mathrm{H}$-bond backbones; among these, $5 \mathrm{H}$-bonds were in similar positions to the SARS-CoV 3CL pro/TA complex (Figure 2): Cys145, Glu166, Arg188 and Thr190 of chain A and Ser1 of chain B. The H-bond interactions of Glu166 and Thr190 
differed between the SARS-CoV 3CL ${ }^{\text {pro}} /$ TA complex and the SARS-CoV-2 3CL pro/TA complex, as Glu166 had a total of $3 \mathrm{H}$-bond interactions with TA in the SARS-CoV $3 \mathrm{CL}^{\text {pro } / T A}$ complex, whereas only one $\mathrm{H}$ bond was formed in the SARS-CoV-2 3CL ${ }^{\text {pro } / T A ~ c o m p l e x, ~ a n d ~ T h r 190 ~ h a d ~ a ~ t o t a l ~ o f ~} 2 \mathrm{H}$-bond interactions

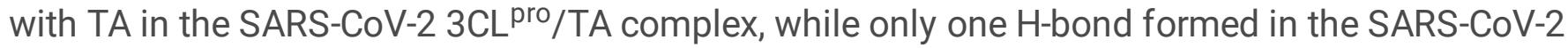
3CL $\mathrm{Lro}^{\mathrm{T}} \mathrm{TA}$ complex.

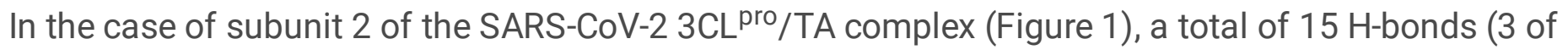

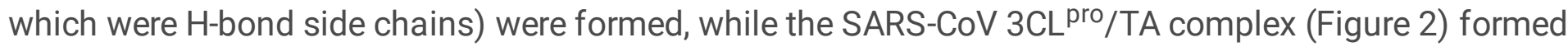
only eight $\mathrm{H}$-bonds ( 5 of which were $\mathrm{H}$-bond side chains). Similarities were noticed in only 2 locations: Cys 145 of chain B (H-bond backbone) and Asn214 of chain A (H-bond side chain). Another notable

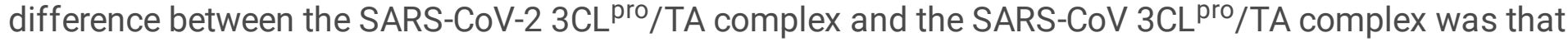
while in SARS-CoV $3 \mathrm{CL}^{\text {pro }}$ TAA complex there was 2 double $\mathrm{H}$-bond interaction ( $\mathrm{H}$-bond side chain) with TA

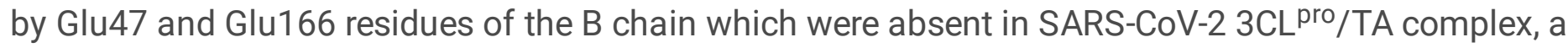
triple $\mathrm{H}$-bond interaction (H-bond backbone) was observed in His164 residue of the B chain. Subunit 1 of the SARS-CoV-2 $3 \mathrm{CL}^{\text {pro }} / \mathrm{TA}$ complex had a total of 12 polar contacts with TA and 7 of these contacts held similar positions in the SARS-CoV 3CL ${ }^{\text {pro } / T A ~ c o m p l e x: ~ r e s i d u e s ~ H i s 41, ~ A s n 142, ~ S e r 144, ~ H i s 163, ~ G I n 189 ~}$ and Thr190 of chain A and Ser1 of chain B. Subunit 2 of the SARS-CoV-2 3CL pro/TA complex had a total of 14 polar contacts with TA, while the SARS-CoV-3CL ${ }^{\text {pro }} / \mathrm{TA}$ complex had only 7 polar contacts, with 5 residues, including Asn214 of chain A and His41, Asn142, Ser144 and GIn189 of chain B, being found to be common. Analyzing the hydrophobic interactions, subunit 1 of the SARS-CoV-2 3CL ${ }^{\text {pro }} / T A$ complex was shown to have a total of 16 hydrophobic contacts with TA among which 7 contacts were shown to

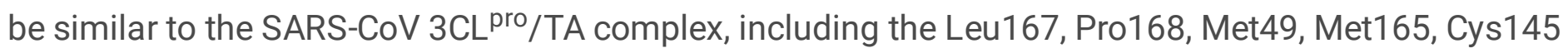
and Phe140 residues of chain A and the Cys 300 residue of chain B. Subunit 2 of the SARS-CoV-2

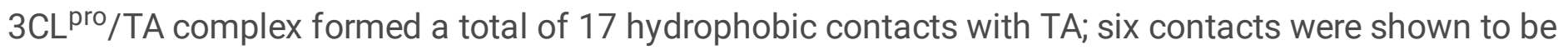
similar to the SARS-CoV 3CL pro/TA complex, including the Val303 residue of chain A and the Cys44, Met49, Leu50, Phe140 and Met165 residues of chain B. From a comparative observation, tannic acid (TA) as a ligand showed a considerably higher binding stability against the SARS-CoV-2 $3 \mathrm{CL}^{\text {pro }}$ enzyme than the SARS-CoV 3CL ${ }^{\text {pro }}$ enzyme.

\subsubsection{Interactions between TF3 with 3CL}

Subunit 1 of the SARS-CoV-2 3CL ${ }^{\text {pro }}$ complex with theaflavin-3-3-digallate (TF3) displayed only $2 \mathrm{H}$-bonds (backbones) between the protein-ligand by residues His164 and Arg188 (Figure 3A), which bears no similarities to the 6 residues from SARS-CoV 3CL ${ }^{\text {pro } / T F 3 ~ c o m p l e x ~ s u b u n i t ~} 1$ (Figure 3C) which formed 7 $\mathrm{H}$-bonds (4 backbones, 3 side chains), since the Glu166 residue of chain A formed $2 \mathrm{H}$-bonds (1 backbone, 1 side chain) with itself. In subunit 2 of the SARS-CoV-2 3CL ${ }^{\text {pro } / T F 3 ~ c o m p l e x ~(F i g u r e ~ 3 B), ~} 4 \mathrm{H}$ bond interactions (backbones) have been observed, of which 2 residues, His164 and Glu166, were similar to those in the SARS-CoV 3CL pro/TF3 complex (Figure 3D) which only formed $2 \mathrm{H}$-bonds in total, although it must be noted that the Glu166 residue of the SARS-CoV 3CL ${ }^{\text {pro } / T F 3 ~ c o m p l e x ~ f o r m e d ~ a ~ H-~}$ 
bond side chain unlike the $\mathrm{H}$-bond backbone of the residue from the SARS-CoV-2 $3 \mathrm{CL}^{\mathrm{pro}} / \mathrm{TF} 3$ complex. SARS-CoV-2 3CL ${ }^{\text {pro } / T F 3 ~ c o m p l e x ~ s u b u n i t ~} 1$ formed 8 polar contacts with TF3, of which 4 were common to the SARS-CoV 3CL ${ }^{\text {pro } / T F 3 ~ c o m p l e x: ~ G l u 189, ~ H i s 41, ~ A s n 142 ~ a n d ~ H i s 163 ; ~ s u b u n i t ~} 2$ formed 5 polar contacts with TF3 and compared to 7 polar contacts in SARS-CoV 3CL ${ }^{\text {pro }}$ TF3 complex subunit 2, where 2 residues were found to be similar: His41 and His164. Subunit 1 of the SARS-CoV-2 3CL pro/TF3 complex formed 4 hydrophobic contacts with TF3, of which 3 residues were common to SARS-CoV $3 \mathrm{CL}^{\text {pro}} / \mathrm{TF} 3$ complex subunit 1: Leu27, Cys145, and Met165. On the other hand, Subunit 2 of the SARS-CoV-2 $3 \mathrm{CL}^{\text {pro}} / \mathrm{TF} 3$ complex formed a total of 7 hydrophobic contacts; when compared with the SARS-CoV $3 \mathrm{CL}^{\text {pro}} / \mathrm{TF} 3$ complex, the same 3 residues as in subunit 1 were found to be common: Leu27, Cys 145 and Met165.

\subsubsection{Interactions between TF2B with $3 \mathrm{CL}^{\text {pro }}$ of SARS-CoV-2 and SARS-CoV}

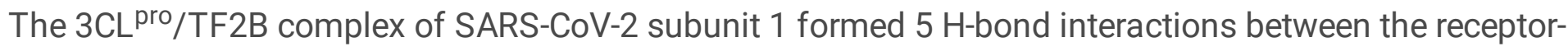
ligand (Figure 4A). Residues Cys145, Glu166, GIn189 formed these interactions, with the Glu166 residue forming $2 \mathrm{H}$-bonds; on the other hand, the SARS-CoV $3 \mathrm{CL}^{\text {pro }} / \mathrm{TF} 2 \mathrm{~B}$ complex formed two H-bond side chains with residue His163 (Figure 4C), and no similarity was identified between these two subunits. In the case of subunit 2 of the SARS-CoV-2 3CL ${ }^{\text {pro } / T F 2 B ~ c o m p l e x ~(F i g u r e ~ 4 B), ~ a ~ t o t a l ~ o f ~} 7 \mathrm{H}$-bonds formed (3 backbones, 4 side chains) by residues Thr25, Asn142, His164 and Glu166; when compared to the $4 \mathrm{H}$ -

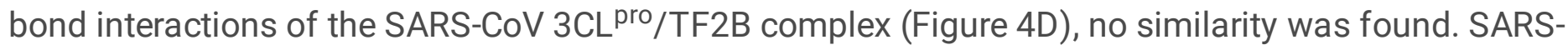
CoV-2 3CL ${ }^{\text {pro } / T F 2 B ~ c o m p l e x ~ s u b u n i t ~} 1$ made a total of 6 polar contacts with TF2B, among which 5 residues, His41, Asn142, Ser144, His163 and Asn189, were similar to the 5 polar contacts of the SARSCoV $3 \mathrm{CL}^{\text {pro }} / \mathrm{TF} 2 \mathrm{~B}$ complex. On the other hand, for subunit 2, both SARS-CoV-2 3CL ${ }^{\text {pro }} / \mathrm{TF}_{2 \mathrm{~B}}$ and SARSCoV 3CL pro/TF2B complexes made 7 similar polar contacts with the ligand: the Thr25, Thr26, His41, Thr45, Asn119, Asn142 and His172 residues from subunit 2. Observing the hydrophobic interactions, it was found that the 5 hydrophobic contacts of the SARS-CoV-2 3CL ${ }^{\text {pro }} / T F 2 B$ complex subunit 1 were similar to 5 out of 6 hydrophobic contacts of the SARS-CoV 3CL pro/TF2B complex subunit 1; the residues were Met49, Phe140, Leu141, Cys145 and Met165. The 6 hydrophobic contacts of SARS-CoV-2 $3 \mathrm{CL}^{\text {pro }} / \mathrm{TF} 2 \mathrm{~B}$ complex subunit 2 were similar to 6 out of the 10 hydrophobic contacts of SARS-CoV

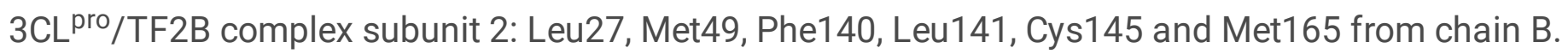

\subsection{Binding free energy calculations}

Differences in the binding free energy $\left(\Delta \mathrm{G}_{\text {bind }}\right)$ for the complexes between ligands and the SARS-CoV2 $3 \mathrm{CL}^{\text {pro }}$ and SARS-CoV $3 \mathrm{CL}^{\text {pro }}$ systems were estimated using the MM/GBSA approach, indicating that all of the complexes are energetically favorable and guided mainly through van der Waals energy $\left(\Delta E_{v d w}\right)$ and the nonpolar free energy of desolvation $\left(\Delta G_{n p o l, s o l}\right)$. Table 1 shows that the ligand reaches a higher affinity in most cases for one of the subunits of dimeric SARS-CoV2 3CL systems, which is consistent with the differences observed in the map of interactions observed through 
structural analyses (Fig. 1-4), and with previous reports where this energetic behavior has been observed $[33,34]$. Average $\Delta G_{\text {bind }}$ values for the ligands coupled at the first and second subunit of SARS-CoV2 $3 C L^{\text {pro }}$ show that TA reaches the highest affinity, followed by TF2B and TF3. Similarly, average $\Delta G_{\text {bind }}$ values for the ligands bound at the two subunits showed that TA binds with the highest affinity to SARSCoV2 $3 \mathrm{CL}^{\text {pro }}$, followed by TF2B and TF3. Interestingly, this tendency is similar to that experimentally reported between these ligands and SARS-CoV2 $3 \mathrm{CL}^{\text {pro }}$ showed $\mathrm{IC}_{50}$ values of 3,7 and $9.5 \mu \mathrm{M}$ for TA, TF2B, TF3, respectively [35].

Comparisons of the affinity of the three compounds for the SARS-CoV2 $3 \mathrm{CL}^{\text {pro }}$ and SARS-CoV $3 \mathrm{CL}^{\text {pro }}$ systems showed that these compounds exhibit a higher affinity for SARS-CoV-2 $3 \mathrm{CL}^{\text {pro }}$ than SARS-CoV $3 \mathrm{CL}^{\text {pro. }}$. Based on this result, it is obvious that TA can be proposed as an anti-COVID-19 clinical drug. TA is an FDA-approved drug that is used in the treatment of cold sores, diaper rash and poison ivy. It is also taken by mouth and used directly for bleeding, chronic diarrhea, bloody urine, dysentery and cancer (https://go.drugbank.com/drugs/DB09372).

\subsection{Per-residue decomposition analysis}

\subsubsection{Per-residue decomposition of TA with $3 \mathrm{CL}^{\text {pro }}$ of SARS-CoV-2 and SARS-CoV}

Analysis of the residues that contribute the most to the $\Delta G_{\text {bind }}$ value for the complex between TA at subunit 1 of SARS-CoV2 $3 \mathrm{CL}^{\text {pro }}$ showed that only those residues whose $\Delta \mathrm{G}_{\text {bind }}$ value is $\geq 2.0 \mathrm{Kcal}$ should be considered: His41, Leu141, Asn142, Cys145, His163, His164, Met165, Glu166, Pro168, Gln189, Thr190 and Ser1 of subunit 2. From these residues, Asn142, Cys145, His163, His164, Glu166, Thr190 and Ser1 of subunit 2 participate in the formation of hydrogen bonds (Figure 1A). In subunit 2 of the SARS-CoV2 3CL pro/TA complex, His41, Met49, Ser139, Leu141, Asn142, Cys145, His163, His164, Met165, Pro168, Gln189 and Thr190, and Phe3, Arg4, Asn214, Val303 and Phe305 of subunit 1 (Figure 1B) contributed importantly to the $\Delta G_{\text {bind }}$ value (Table 2). Among these residues, His41, Ser139, Cys145, His 163, His 164 and Thr190 of subunit 2, and Arg4 and Asn214 of subunit 1 formed hydrogen bonds. These results indicated that a similar type of residue contributed to mainly stabilizing the complexes between TA at subunit 1 and 2 of SARS-CoV2 3CL ${ }^{\text {pro }}$. In fact, the presence of 10 residues: His41, Leu141, Asn142, Cys145, His163, His164, Met165, Pro168, Gln189 and Thr190 was observed in the ligand stabilization at both subunits of SARS-CoV2 $3 \mathrm{CL}^{\text {pro. }}$.

For the complex between TA and subunit 1 of SARS-CoV 3CL ${ }^{\text {pro }}$, it was observed that Met49, Leu50, Leu141, Cys145, Met165, Glu166, Leu167 and GIn189 are the major contributors to the $\Delta G_{\text {bind }}$ value (Table 2). Of these, Cys145, Glu166 and GIn189 are involved in forming hydrogen bonds and the rest of the residues form van der Waals interactions. Complexes at subunit 2 of SARS-CoV $3 \mathrm{CL}^{\text {pro }}$ showed that Ala46, Glu47, Met49, Cys145, and Glu166 of subunit 2, and Gln189 and Val303 of chain A are the main contributors of $\Delta G_{\text {bind }}$ value. Of these residues, Glu47, Cys 145 and Glu166 of subunit 2 and Val303 of subunit 1 formed hydrogen bonds. A comparison of complexation at subunit 1 and 2 indicated that a 
dissimilar residue contributed the most to the stabilization of the complexes at both subunits, where just the participation of Cys145 and Glu166 was appreciated in both subunits of SARS-CoV 3CL ${ }^{\text {pro. }}$.

\subsubsection{Per-residue decomposition of TF3 with 3CL ${ }^{\text {pro }}$ of SARS-CoV-2 and SARS-CoV}

Analysis of residues between TF3 at subunit 1 of SARS-CoV2 3CL ${ }^{\text {pro }}$ showed that Thr25, Thr26, Leu27, His41, Met49, Asn142, Gly143, Ser144, Cys145, His163, His164, Met165, Glu166, Asp187, Arg188 and GIn189 contributed the most to the binding (Table 2). Of these residues, Arg188 and His164 form hydrogen bonds with the polar groups of TF3 (Figure 3A).

At the second subunit, Leu27, Pro39, His41, Thr45, Met49, Leu50, Cys145, His164, Met165, Glu166, Leu167, Asp187, Arg188 and GIn189 were the main contributors to the $\Delta G_{\text {bind }}$ values, of which only His164, Glu166, Asp187 and GIn192 were observed to form hydrogen bonds (Figure 3B). Similar to that observed for the complexes between TA and SARS-CoV2 3CL ${ }^{\text {pro }}$, complexes between TF3 and SARS-CoV2 $3 \mathrm{CL}^{\text {pro }}$ shared a high number of similar residues: Leu27, His41, Met49, Cys145, His164, Met165, Glu166, Asp187, Arg188 and GIn189. Residues between TF3 and subunit 1 of SARS-CoV 3CL ${ }^{\text {pro }}$ showed that Leu27, His41, Thr45, Ala46, Glu47, Asp48, Phe140, Leu141, Asn142, Cys145, His163, Met165, Glu166 and Gln189 (Table 2) contributed the most to the $\Delta G_{\text {bind }}$; of these residues, Ala46, Asp48, Glu47, Asn142 and Glu166 formed hydrogen bonds with polar moieties of TF3 (Figure 3C). In the second subunit, it is observed that Thr25, Thr26, Leu27, His41, Val42, Phe140, Asn142, Gly143, Ser144, Cys145, His163, His164, Met165 and Glu166 are the main contributors to the affinity. Of these residues, only His164 and Glu166 form hydrogen bonds, with the rest making polar and non-polar contacts. Comparative analysis of the complexes between TF3 and SARS-CoV2 $3 \mathrm{CL}^{\text {pro }}$ and SARS-CoV $3 \mathrm{CL}^{\text {pro }}$ shows that the complexes shared eight residues in common: Leu27, His41, Phe140, Asn142, Cys145, His163, M165 and Glu166.

\subsubsection{Per-residue decomposition of TF2B with $3 \mathrm{CL}^{\text {pro }}$ of SARS-CoV-2 and SARS-CoV}

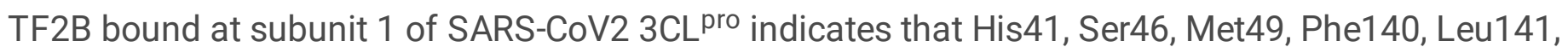
Asn142, Gly143, Ser144, Cys145, His163, Met165, Glu166, Asp187, Arg188 and GIn189 are the main stabilizers of the complex, with Cys 145 , Gln189 and Glu166 forming hydrogen bonds with polar atoms of TF2B and the rest forming polar and non-polar interactions (Figure 4A). The complex with TF2B at subunit 2 of SARS-CoV2 3CL ${ }^{\text {pro }}$ shows that this was mainly stabilized by Thr25, Thr26, Leu27, Ser46, Met49, Phe140, Leu141, Asn142, Gly143, Cys145, His163, His164, Met165, Glu166 and Gln189; of these residues, Thr26, Asn142, His164 and Glu166 form hydrogen bonds with the polar groups of TF2B (Figure $4 \mathrm{~B})$. Comparison of the residues involved in the stabilization of TF2B in both subunits shows a high number of similar residues: Ser46, Met49, Phe140, Leu141, Asn142, Gly143, Cys145, His163, His164, Met165, Glu166 and GIn189.

In subunit 1 of SARS-CoV 3CL ${ }^{\text {pro, }}$,TF2B was mainly stabilized by His41, Ala46, Met49, Phe140, Leu141, Asn142, Gly43, Ser144, Cys145, His163, Met165 and GIn189, of which only His163 formed a hydrogen bond, with the rest making polar and non-polar interactions (Figure 4C). In contrast, in subunit 2 of SARS- 
CoV 3CL ${ }^{\text {pro }}$, TF2B was mainly stabilized by Thr25, Thr26, Leu27, His41, Val42, Cys44, Thr45, Ala46, Met49, Tyr118, Asn119, Leu141, Ans142, Gly143, Cys145, Met165 and His172, with His41, Gly143 and His172 forming hydrogen bonds (Figure 4D). Comparison of the residues in both subunits of SARS-CoV $3 \mathrm{CL}^{\text {pro }}$ indicates that eight residues are present in both subunits: His41, Ala46, Met49, Leu141, Asn142, Gly43, Cys145 and Met165, a lower number than that appreciated for the complexes between TF2B and SARS-CoV-2 3CL ${ }^{\text {pro. }}$.

In general, this analysis takes into consideration the participation of His41 and Cys145, two conserved residues [50], in molecular recognition and highlights the relevance of other residues (Met49, Asn142, His163, Met165, Glu166, Asp187 and GIn189) in the stabilization of ligands; these are similar residues to those previously observed for ligand stabilization in SARS-CoV-2 $3 \mathrm{CL}^{\text {pro }}$ and SARS-CoV $3 \mathrm{CL}^{\text {pro }}$ systems $[33,34]$.

\section{Conclusion}

In this contribution, we first performed the docking studies of three plant-derived compounds, which were previously reported to be inhibitors of SARS-CoV $3 \mathrm{CL}^{\text {pro }}$, on dimeric SARS-CoV-2 $3 \mathrm{CL}^{\text {pro }}$ and SARS-CoV $3 \mathrm{CL}^{\text {pro }}$, after which 100-ns-long MD simulations combined with the MM/GBSA approach were employed to compare results. Our results showed that the binding affinity of the three natural compounds forming complex with SARS-CoV $3 \mathrm{CL}^{\text {pro }}$ reproduced the experimental affinity tendency, in which tannic acid showed the highest affinity. Comparative of the binding affinity between the three compounds and SARSCoV-2 $3 \mathrm{CL}^{\text {pro }}$ and SARS-CoV $3 \mathrm{CL}^{\text {pro }}$ revealed that the compounds exhibited a higher affinity for SARSCoV-2 $3 \mathrm{CL}^{\text {pro }}$ than SARS-CoV $3 \mathrm{CL}^{\text {pro, }}$, suggesting that these three compounds may have potential as inhibitors of SARS-CoV-2 $3 \mathrm{CL}^{\text {pro }}$. In addition, per-residue free energy decomposition allowed hot-spot residues (His41, Met49, Cys145, Asn142, His163, Met165, Glu166, Asp187 and Gln189) to be identified which contribute importantly to the total binding affinity. Of these residues, His41 and Cys145 are conserved residues that are considered important for ligand binding.

\section{Declarations}

\section{Acknowledgements}

The work was supported by grants from CONACYT (CB-A1-S-21278) and SIP/IPN (20210516).

\section{Competing interests}

The authors declare no competing interests.

\section{References}


1. C. Huang et al., "Clinical features of patients infected with 2019 novel coronavirus in Wuhan, China," Lancet, vol. 395, no. 10223, pp. 497-506, Feb. 2020, DOI: 10.1016/S0140-6736(20)30183-5.

2. W. Guan et al., "Clinical Characteristics of Coronavirus Disease 2019 in China," N. Engl. J. Med., vol. 382, no. 18, pp. 1708-1720, Apr. 2020, DOI: 10.1056/nejmoa2002032.

3. J. Liu et al., "Overlapping and discrete aspects of the pathology and pathogenesis of the emerging human pathogenic coronaviruses SARS-CoV, MERS-CoV, and 2019-nCoV," J. Med. Virol., vol. 92, no. 5, pp. 491-494, May 2020, DOI: 10.1002/jmv.25709.

4. S. Ludwig and A. Zarbock, "Coronaviruses and SARS-CoV-2: A Brief Overview," Anesth. Analg., pp. 93-96, 2020, DOI: 10.1213/ANE.0000000000004845.

5. V. Brinks and O. Ibert, "From Corona Virus to Corona Crisis: The Value of An Analytical and Geographical Understanding of Crisis," Tijdschr. voor Econ. en Soc. Geogr., vol. 111, no. 3, pp. 275287, Jul. 2020, DOI: 10.1111/tesg.12428.

6. Li G, De Clercq E (2020) Therapeutic options for the 2019 novel coronavirus (2019-nCoV). Nat Rev Drug Discov 19:149-150.

7. J. L. Nguyen, W. Yang, K. Ito, T. D. Matte, J. Shaman, and P. L. Kinney, "Seasonal influenza infections and cardiovascular disease mortality," JAMA Cardiol., vol. 1, no. 3, pp. 274-281, Jun. 2016, DOI: 10.1001/jamacardio.2016.0433.

8. Kwong, J. C., Schwartz, K. L., Campitelli, M. A., Chung, H., Crowcroft, N. S., Karnauchow, T., ... \& Gubbay, J. B. (2018). Acute myocardial infarction after laboratory-confirmed influenza infection. New England Journal of Medicine, 378(4), 345-353.

9. N. Petrosillo, G. Viceconte, O. Ergonul, G. Ippolito, and E. Petersen, “COVID-19, SARS and MERS: are they closely related?," Clin. Microbiol. Infect., vol. 26, no. 6, pp. 729-734, Jun. 2020, DOI: 10.1016/j.cmi.2020.03.026.

10. M. Xie and Q. Chen, "Insight into 2019 novel coronavirus - An updated interim review and lessons from SARS-CoV and MERS-CoV," Int. J. Infect. Dis., vol. 94, pp. 119-124, May 2020, DOI: 10.1016/j.ijid.2020.03.071.

11. D. Benvenuto, M. Giovanetti, A. Ciccozzi, S. Spoto, S. Angeletti, and M. Ciccozzi, "The 2019-new coronavirus epidemic: Evidence for virus evolution,” J. Med. Virol., vol. 92, no. 4, pp. 455-459, Apr. 2020, DOI: 10.1002/jmv.25688.

12. Zhou, P., Yang, X. L., Wang, X. G., Hu, B., Zhang, L., Zhang, W., ... \& Shi, Z. L. (2020). A pneumonia outbreak associated with a new coronavirus of probable bat origin. nature, 579(7798), 270-273.

13. C. Ceraolo and F. M. Giorgi, "Genomic variance of the 2019-nCoV coronavirus," J. Med. Virol., vol. 92, no. 5, pp. 522-528, May 2020, DOl: 10.1002/jmv.25700.

14. Masters, P. S. (2006). The molecular biology of coronaviruses. Advances in virus research, 66, 193292.

15. Y. Chen, Q. Liu, and D. Guo, "Emerging coronaviruses: Genome structure, replication, and pathogenesis," J. Med. Virol., vol. 92, no. 4, pp. 418-423, Apr. 2020, DOI: 10.1002/jmv.25681. 
16. Gordon, D. E., Jang, G. M., Bouhaddou, M., Xu, J., Obernier, K., White, K. M., ... \& Krogan, N. J. (2020). A SARS-CoV-2 protein interaction map reveals targets for drug repurposing. Nature, 583(7816), 459468.

17. J. Ziebuhr, G. Heusipp, and S. G. Siddell, "Biosynthesis, purification, and characterization of the human coronavirus 229E 3C-like proteinase.," J. Virol., vol. 71, no. 5, pp. 3992-3997, 1997, DOI: 10.1128/jvi.71.5.3992-3997.1997.

18. J. Ziebuhr, E. J. Snijder, and A. E. Gorbalenya, “Virus-encoded proteinases and proteolytic processing in the Nidovirales," J. Gen. Virol., vol. 81, no. 4, pp. 853-879, 2000, DOI: 10.1099/0022-1317-81-4853.

19. R. A. Khailany, M. Safdar, and M. Ozaslan, “Genomic characterization of a novel SARS-CoV-2,” Gene Reports, vol. 19, Jun. 2020, DOI: 10.1016/j.genrep.2020.100682.

20. Y. M. Báez-Santos, S. E. St. John, and A. D. Mesecar, "The SARS-coronavirus papain-like protease: Structure, function and inhibition by designed antiviral compounds," Antiviral Res., vol. 115, pp. 2138, Mar. 2015, DOI: 10.1016/j.antiviral.2014.12.015.

21. Zhang, L., Lin, D., Sun, X., Curth, U., Drosten, C., Sauerhering, L., ... \& Hilgenfeld, R. (2020). Crystal structure of SARS-CoV-2 main protease provides a basis for design of improved a-ketoamide inhibitors. Science, 368(6489), 409-412.

22. P. C. Y. Woo, Y. Huang, S. K. P. Lau, and K. Y. Yuen, "Coronavirus genomics and bioinformatics analysis," Viruses, vol. 2, no. 8, pp. 1805-1820, Sep. 2010, DOI: 10.3390/v2081803.

23. M. Slaoui and M. Hepburn, “Developing Safe and Effective Covid Vaccines - Operation Warp Speed's Strategy and Approach," N. Engl. J. Med., Aug. 2020, DOI: 10.1056/nejmp2027405.

24. Zhang, L., Lin, D., Kusov, Y., Nian, Y., Ma, Q., Wang, J., ... \& Hilgenfeld, R. (2020). a-Ketoamides as broad-spectrum inhibitors of coronavirus and enterovirus replication: structure-based design, synthesis, and activity assessment. Journal of medicinal chemistry, 63(9), 4562-4578.

25. R. Hilgenfeld, "From SARS to MERS: crystallographic studies on coronaviral proteases enable antiviral drug design," FEBS J., vol. 281, no. 18, pp. 4085-4096, Sep. 2014, DOI: 10.1111/febs.12936.

26. S. Şimşek Yavuz and S. Ünal, “Antiviral treatment of covid-19,” Turkish J. Med. Sci., vol. 50, no. SI-1, pp. 611-619, 2020, DOI: 10.3906/sag-2004-145.

27. O. Mitjà and B. Clotet, "Use of antiviral drugs to reduce COVID-19 transmission," Lancet Glob. Heal., vol. 8, no. 5, pp. e639-e640, May 2020, DOl: 10.1016/S2214-109X(20)30114-5.

28. N. Sinha and G. Balayla, “Hydroxychloroquine and covid-19," Postgrad. Med. J., vol. 96, no. 1139, pp. 550-555, 2020, DOI: 10.1136/postgradmedj-2020-137785.

29. J. H. Beigel et al., "Remdesivir for the Treatment of Covid-19 - Preliminary Report," N. Engl. J. Med., May 2020, DOI: 10.1056/nejmoa2007764.

30. M. K. Hasan et al., "Structural analogues of existing anti-viral drugs inhibit SARS-CoV-2 RNA dependent RNA polymerase: A computational hierarchical investigation," Nov. 2020, DOI: 10.21203/rs.3.rs-103595/v1. 
31. Andrianov AM, Kornoushenko YV, Karpenko AD, Bosko IP, Tuzikov AV (2020) Computational discovery of small drug-like compounds as potential inhibitors of SARS-CoV-2 main protease. $\mathrm{J}$ Biomol Struct Dyn:1-13

32. Jiménez-Alberto A, Ribas-Aparicio RM, Aparicio-Ozores G, Castelán-Vega JA (2020) Virtual screening of approved drugs as potential SARS-CoV-2 main protease inhibitors. Comput Biol Chem 107325

33. Bello, M., Martínez-Muñoz, A., \& Balbuena-Rebolledo, I. (2020). Identification of saquinavir as a potent inhibitor of dimeric SARS-CoV2 main protease through MM/GBSA. Journal of molecular modeling, 26(12), 1-11.

34. Bello M. Prediction of potential inhibitors of the dimeric SARS-CoV2 main proteinase through the MM/GBSA approach. J Mol Graph Model. 2020 Dec;101:107762

35. Graziano V, McGrathWJ, Yang L,Mangel WF (2006) SARS CoV main proteinase: the monomer- dimer equilibrium dissociation constant. Biochemistry 45(49):14632-14641

36. C. N. Chen et al., "Inhibition of SARS-CoV 3C-like protease activity by theaflavin-3,3'- digallate (TF3)," Evidence-based Complement. Altern. Med., vol. 2, no. 2, pp. 209-215, Jun. 2005, DOI: 10.1093/ecam/neh081.

37. Frisch MJT, GW Schlegel HB, Scuseria GE et al (2009) Gaussian Gaussian Inc.

38. G.M. Morris, R. Huey, W. Lindstrom, M.F. Sanner, R.K. Belew, D.S. Goodsell, A.J. Olson, J. Comput. Chem. 30 (2009) $2785 \mathrm{e} 2791$.

39. D.A. Case, T.E. Cheatham, T. Darden, H. Gohlke, R. Luo, K.M. Merz Jr., R.J. Woods, J. Comput. Chem. 26 (2005) $1668 \mathrm{e} 1688$.

40. Y. Duan, C. Wu, S. Chowdhury, M.C. Lee, G. Xiong, W. Zhang, P. Kollman, J. Comput. Chem. 24 (2003) $1999 \mathrm{e} 2012$.

41. J. Wang, R.M. Wolf, J.W. Caldwell, P.A. Kollman, D.A. Case, J. Comput. Chem. 25 (2004) 1157e1174

42. W.L. Jorgensen, J. Chandrasekhar, J.D. Madura, R.W. Impey, M.L. Klein, J. Chem. Phys. 79 (1983) $926 \mathrm{e} 935$.

43. T. Darden, D. York, L. Pedersen, J. Chem. Phys. 98 (1993) 10089e10092.

44. W.F. Van Gunsteren, H.J.C. Berendsen, Mol. Phys. 34 (1977) 1311e1327.

45. H.J.C. Berendsen, J.P.M. Postma, W.F. van Gunsteren, A. DiNola, J.R. Haak, J. Chem. Phys. 81 (1984) 3684e3690. B.R. Miller, T.D. McGee, J.M. Swails, N. Homeyer, H. Gohlke, A.E. Roitberg, J. Chem. Theory Comput. 8 (2012) 3314e3321.

46. Schrödinger, LLC. Maestro, Version 10.5. New York, NY, USA: 2016-1

47. Miller, B. R., McGee, T. D., Swails, J. M., Homeyer, N., Gohlke, H., \& Roitberg, A. E. (2012). MMPBSA.py: An efficient program for end-state free energy calculations. Journal of Chemical Theory and Computation, 8(9), 3314-3321. https://doi.org/10.1021/ct300418h

48. Gohlke, H., \& Case, D. A. (2004). Converging free energy estimates: MM-PB (GB) SA studies on the protein-protein complex Ras-Raf. Journal of computational chemistry, 25(2), 238-250. 
49. Onufriev, A., Bashford, D., \& Case, D. A. (2004). Exploring protein native states and large-scale conformational changes with a modified generalized born model. Proteins: Structure, Function, and Bioinformatics, 55(2), 383-394.

50. Bello, M., \& García-Hernández, E. (2014). Ligand entry into the calyx of $\beta$ lactoglobulin. Biopolymers, 101(7), 744-757.

51. Nukoolkarn, V., Lee, V. S., Malaisree, M., Aruksakulwong, O., \& Hannongbua, S. (2008). Molecular dynamic simulations analysis of ritronavir and lopinavir as SARS-CoV 3CLpro inhibitors. Journal of theoretical biology, 254(4), 861-867.

\section{Tables}

Table 1. Binding free energy components of complexes between ligands and SARS-CoV-2 3CL ${ }^{\text {pro }}$ (in units of $\mathrm{kcal} / \mathrm{mol}$ ). 


\begin{tabular}{|c|c|c|c|c|c|}
\hline Sistema & $\Delta E_{v d w}$ & $\Delta E_{e l e}$ & $\Delta G_{e l e, s o l}$ & $\Delta G_{n p o l, s o l}$ & $\Delta G_{m m g b s a}$ \\
\hline $\begin{array}{l}\text { SARS-CoV-2 TA- } \\
\text { sub1 }\end{array}$ & $\begin{array}{l}-127.72 \\
(7.5)\end{array}$ & $\begin{array}{l}-92.62 \\
(16.98)\end{array}$ & $\begin{array}{l}160.15 \\
(14.34)\end{array}$ & $\begin{array}{l}-14.90 \\
(0.80)\end{array}$ & $\begin{array}{l}-75.11 \\
(7.5)\end{array}$ \\
\hline $\begin{array}{l}\text { SARS-CoV-2 TA- } \\
\text { sub2 }\end{array}$ & $\begin{array}{l}-134.35 \\
(6.5)\end{array}$ & $\begin{array}{l}-110.38 \\
(22.48)\end{array}$ & $\begin{array}{l}189.13 \\
(18.24)\end{array}$ & $\begin{array}{l}-17.53 \\
(0.60)\end{array}$ & $\begin{array}{l}-73.13 \\
(7.1)\end{array}$ \\
\hline $\begin{array}{l}\text { SARS-CoV- } \\
2_{\text {TF3-sub1 }}\end{array}$ & $\begin{array}{l}-58.22 \\
(4.7)\end{array}$ & $\begin{array}{l}-37.47 \\
(7.4)\end{array}$ & $\begin{array}{l}75.07 \\
(5.4)\end{array}$ & $\begin{array}{l}-7.65 \\
(0.40)\end{array}$ & $\begin{array}{l}-28.27 \\
(4.3)\end{array}$ \\
\hline $\begin{array}{l}\text { SARS-CoV- } \\
2_{\text {TF3-sub2 }}\end{array}$ & $\begin{array}{l}-64.26 \\
(5.0)\end{array}$ & $\begin{array}{l}-55.98 \\
(9.4)\end{array}$ & $\begin{array}{l}92.38 \\
(7.8)\end{array}$ & $\begin{array}{l}-8.01 \\
(0.34)\end{array}$ & $\begin{array}{l}-35.88 \\
(4.5)\end{array}$ \\
\hline $\begin{array}{l}\text { SARS-CoV- } \\
2_{\text {TF2B-sub1 }}\end{array}$ & $\begin{array}{l}-61.08 \\
(5.0)\end{array}$ & $\begin{array}{l}-86.30 \\
(12.9)\end{array}$ & $\begin{array}{l}109.28 \\
(10.0)\end{array}$ & $\begin{array}{l}-7.87 \\
(0.30)\end{array}$ & $\begin{array}{l}-45.97 \\
(4.0)\end{array}$ \\
\hline $\begin{array}{l}\text { SARS-CoV- } \\
2_{\text {TF2B-sub2 }}\end{array}$ & $\begin{array}{l}-50.46 \\
(5.8)\end{array}$ & $\begin{array}{l}-57.06 \\
(17.7)\end{array}$ & $\begin{array}{l}81.96 \\
(13.0)\end{array}$ & $\begin{array}{l}-6.68 \\
(0.73)\end{array}$ & $\begin{array}{l}-32.24 \\
(6.6)\end{array}$ \\
\hline $\begin{array}{l}\text { SARS-CoV } \\
\text { sub1 }\end{array}$ & $\begin{array}{l}-95.40 \\
(7.8)\end{array}$ & $\begin{array}{l}-134.79 \\
(21.7)\end{array}$ & $\begin{array}{l}183.47 \\
(18.0)\end{array}$ & $\begin{array}{l}-13.53 \\
(0.73)\end{array}$ & $\begin{array}{l}-60.26 \\
(8.8)\end{array}$ \\
\hline $\begin{array}{l}\text { SARS-CoV } \\
\text { sub2 }\end{array}$ & $\begin{array}{l}-62.45 \\
(7.4)\end{array}$ & $\begin{array}{l}-148.31 \\
(19.55)\end{array}$ & $\begin{array}{l}188.58 \\
(16.38)\end{array}$ & $\begin{array}{l}-10.44 \\
(0.60)\end{array}$ & $\begin{array}{l}-32.63 \\
(4.8)\end{array}$ \\
\hline $\begin{array}{l}\text { SARS-CoV } \\
\text { sfF3- } \\
\text { sub1 }\end{array}$ & $\begin{array}{l}-65.13 \\
(6.0)\end{array}$ & $\begin{array}{l}-66.67 \\
(16.8)\end{array}$ & $\begin{array}{l}104.84 \\
(13.0)\end{array}$ & $\begin{array}{l}-8.53 \\
(0.50)\end{array}$ & $\begin{array}{l}-35.48 \\
(.3)\end{array}$ \\
\hline $\begin{array}{l}\text { SARS-CoV } \\
\text { sF3- } \\
\text { sub2 }\end{array}$ & $\begin{array}{l}-52.59 \\
(4.1)\end{array}$ & $\begin{array}{l}-52.83 \\
(11.4)\end{array}$ & $\begin{array}{l}86.65 \\
(10.2)\end{array}$ & $\begin{array}{l}-6.52 \\
(0.46)\end{array}$ & $\begin{array}{l}-25.29 \\
(3.4)\end{array}$ \\
\hline $\begin{array}{l}\text { SARS-CoV } \\
\text { TF2B- } \\
\text { sub1 }\end{array}$ & $\begin{array}{l}-50.94 \\
(5.1)\end{array}$ & $\begin{array}{l}-33.25 \\
(9.3)\end{array}$ & $\begin{array}{l}63.95 \\
(9.6)\end{array}$ & $\begin{array}{l}-5.38 \\
(0.60)\end{array}$ & $\begin{array}{l}-25.63 \\
(4.0)\end{array}$ \\
\hline $\begin{array}{l}\text { SARS-CoV } \\
\text { TF2B- } \\
\text { sub2 }\end{array}$ & $\begin{array}{l}-46.94 \\
(5.7)\end{array}$ & $\begin{array}{l}-82.32 \\
(13.5)\end{array}$ & $\begin{array}{l}110.97 \\
(10.0)\end{array}$ & $\begin{array}{l}-7.09 \\
(0.38)\end{array}$ & $\begin{array}{l}-25.38 \\
(4.3)\end{array}$ \\
\hline
\end{tabular}

Table 2. Per-residue free energy for complexes between TA, TF3 and TF2B with SARS-CoV-2 3CL pro (values $\mathrm{kcal} / \mathrm{mol}$ ). 


\begin{tabular}{|c|c|c|c|c|c|c|c|}
\hline Residue & $\begin{array}{l}\text { SARS-CoV- } \\
\text { 2 TF2B-sub1 }\end{array}$ & $\begin{array}{l}\text { SARS- } \\
\text { CoV-2 TF3- } \\
\text { sub1 }\end{array}$ & $\begin{array}{l}\text { SARS-CoV- } \\
2_{\text {TF2B-sub1 }}\end{array}$ & Residue & $\begin{array}{l}\text { SARS- } \\
\text { CoV- } \\
2_{\text {TF2B- }} \\
\text { sub2 }\end{array}$ & $\begin{array}{l}\text { SARS- } \\
\text { CoV- } \\
\text { 2 TF3-sub2 }^{\text {The }}\end{array}$ & $\begin{array}{l}\text { SARS- } \\
\text { CoV-- } \\
2_{\text {TF2B-sub2 }}\end{array}$ \\
\hline T25(A) & & -2.016 & & $\mathrm{~T} 25(\mathrm{~B})$ & & & -3.566 \\
\hline T26(A) & & -1.132 & & T26(B) & -0.729 & & -1.218 \\
\hline L27(A) & -0.896 & -0.92 & & L27(B) & -1.595 & -0.715 & -0.694 \\
\hline $\mathrm{H} 41(\mathrm{~A})$ & -2.256 & -1.611 & -1.841 & P39(B) & & -0.96 & \\
\hline S46(A) & & & -1.516 & $\mathrm{R} 40$ (B) & & & \\
\hline M49(A) & -0.967 & -2.607 & -2.32 & $\mathrm{H} 41$ (B) & -2.783 & -2.975 & \\
\hline $\mathrm{F} 140(\mathrm{~A})$ & -1.276 & & -1.129 & V42(B) & -0.532 & & \\
\hline L141(A) & -2.081 & & -1.091 & C44(B) & -0.926 & & \\
\hline N142(A) & -4.095 & -1.989 & -1.746 & $\mathrm{~T} 45(\mathrm{~B})$ & & -0.626 & \\
\hline G143(A) & -1.505 & -1.018 & -1.423 & S46(B) & -1.392 & & -0.858 \\
\hline S144(A) & -1.726 & -0.542 & -1.318 & M49(B) & -3.113 & -3.92 & -2.247 \\
\hline C145(A) & -2.28 & -2.279 & -2.262 & L50(B) & -1.293 & -0.804 & \\
\hline $\mathrm{H} 163(\mathrm{~A})$ & -2.764 & -0.971 & -1.104 & S139(B) & -2.661 & & \\
\hline $\mathrm{H} 164(\mathrm{~A})$ & -2.704 & -1.779 & & F140(B) & -0.927 & & -1.118 \\
\hline M165(A) & -4.279 & -3.098 & -2.557 & L141(B) & -2.325 & & -1.036 \\
\hline E166(A) & -2.067 & -0.71 & -5.495 & N142(B) & -2.555 & & -2.284 \\
\hline L167(A) & -1.19 & & & G143(B) & -1.74 & & -0.921 \\
\hline P168(A) & -3.036 & & & S144(B) & -0.795 & & \\
\hline $\mathrm{H} 172(\mathrm{~A})$ & -1.006 & & & C145(B) & -2.344 & -1.156 & -1.043 \\
\hline D187(A) & -1.324 & -1.202 & -1.034 & H163(B) & -2.018 & & -2.134 \\
\hline R188(A) & -1.434 & -0.88 & -1.005 & H164(B) & -3.753 & -2.115 & -1.061 \\
\hline Q189(A) & -2.6 & -2.025 & -3.219 & M165(B) & -2.825 & -4.219 & -2.373 \\
\hline T190(A) & -2.775 & & & E166(B) & -0.046 & -1.303 & -4.439 \\
\hline A191(A) & -1.448 & & & L167(B) & -0.987 & -0.782 & \\
\hline Q192(A) & -1.024 & & & P168(B) & -2.404 & & \\
\hline S1(B) & 3.782 & & & D187(B) & -0.751 & -2.718 & \\
\hline
\end{tabular}




\begin{tabular}{|c|c|c|c|c|c|}
\hline G2(B) & -1.817 & R188(B) & -0.908 & -1.739 & \\
\hline F3(B) & -1.129 & Q189(B) & -3.174 & -1.733 & -0.702 \\
\hline A210(B) & -0.899 & T190(B) & -2.18 & & \\
\hline I213(B) & -2.123 & A191(B) & -1.652 & & \\
\hline N214(B) & -1.274 & Q192(B) & -1.133 & -1.224 & \\
\hline G215(B) & -0.564 & $\mathrm{~F} 3(\mathrm{~A})$ & -2.679 & & \\
\hline $\mathrm{R} 217(\mathrm{~B})$ & -1.187 & $\mathrm{R} 4(\mathrm{~A})$ & -2.022 & & \\
\hline V296(B) & -1.244 & $\mathrm{I} 213(\mathrm{~A})$ & -1.577 & & \\
\hline Q299(B) & -2.415 & $\mathrm{~N} 214(\mathrm{~A})$ & -2.507 & & \\
\hline C300(B) & -0.856 & Q299(A) & -0.857 & & \\
\hline V303(B) & -1.776 & $\mathrm{C} 300(\mathrm{~A})$ & -1.302 & & \\
\hline \multirow[t]{4}{*}{ F305(B) } & -0.658 & V303(A) & -2.595 & & \\
\hline & & T304(A) & -1.086 & & \\
\hline & & F305(A) & -2.438 & & \\
\hline & & Q306(A) & & & \\
\hline
\end{tabular}

Sub1 and sub2 denote interactions between ligand and subunits 1 or 2 of dimeric SARS-CoV2 $3 \mathrm{CL}^{\text {pro }}$. (A) and $(\mathrm{B})$ denote chain $\mathrm{A}$ and $\mathrm{B}$.

Table 3. Per-residue free energy for complexes between TA, TF3 and TF2B with SARS-CoV $3 \mathrm{CL}^{\text {pro }}$ (values $\mathrm{kcal} / \mathrm{mol})$. 


\begin{tabular}{|c|c|c|c|c|c|c|c|}
\hline Residue & $\begin{array}{l}\text { SARS- } \\
\text { CoVV }_{\text {TA- }} \\
\text { sub1 }\end{array}$ & $\begin{array}{l}\text { SARS- } \\
\text { CoV }_{\text {TF3- }} \\
\text { sub1 }\end{array}$ & $\begin{array}{l}\text { SARS- } \\
\text { CoV } \\
\text { sF2B- } \\
\text { sub1 }\end{array}$ & Residue & $\begin{array}{l}\text { SARS- } \\
\text { CoVV }_{\text {TA- }} \\
\text { sub2 }\end{array}$ & $\begin{array}{l}\text { SARS- } \\
\text { CoV }_{\text {TF3- }} \\
\text { sub2 }\end{array}$ & $\begin{array}{l}\text { SARS- } \\
\text { CoV }_{\text {TF2B- }} \\
\text { sub2 }\end{array}$ \\
\hline L27(A) & & -0.765 & & T25(B) & -0.818 & -1.057 & -1.064 \\
\hline $\mathrm{H} 41(\mathrm{~A})$ & -0.794 & -2.337 & -0.735 & T26(B) & & -0.797 & -0.666 \\
\hline C44(A) & -0.843 & & & L27(B) & & -1.73 & -2.922 \\
\hline T45(A) & -1.087 & -0.599 & & L32(B) & & & \\
\hline $\mathrm{A} 46(\mathrm{~A})$ & -1.595 & -2.529 & -0.526 & $\mathrm{H} 41$ (B) & -1.255 & -2.362 & -3.052 \\
\hline E47(A) & & -0.247 & & V42(B) & & -0.643 & -0.779 \\
\hline D48(A) & & -1.205 & & C44(B) & -0.885 & & -0.997 \\
\hline M49(A) & -3.74 & & -2.172 & T45(B) & -1.13 & & -0.777 \\
\hline L50(A) & -2.404 & & & A46(B) & -3.288 & & -0.654 \\
\hline N51(A) & -0.69 & & & E47(B) & -3.643 & & \\
\hline F140(A) & -1.591 & -1.292 & -0.879 & M49(B) & -2.39 & & -0.621 \\
\hline L141(A) & -2.434 & -0.952 & -1.679 & L50(B) & -1.803 & & \\
\hline $\mathrm{N} 142(\mathrm{~A})$ & -1.704 & -2.207 & -3.658 & Y118(B) & & & -0.836 \\
\hline G143(A) & -0.931 & & -1.59 & N119(B) & & & -0.716 \\
\hline S144(A) & -1.247 & & -0.783 & F140(B) & -0.95 & -0.774 & \\
\hline C145(A) & -2.048 & -0.973 & -1.006 & L141(B) & -1.614 & & -1.034 \\
\hline S146(A) & & & & N142(B) & -0.869 & -2.54 & -1.088 \\
\hline C147(A) & & & & G143(B) & -1.273 & -3.052 & -1.954 \\
\hline $\mathrm{H} 163(\mathrm{~A})$ & -1.024 & -1.723 & -2.154 & S144(B) & -0.82 & -1.031 & \\
\hline $\mathrm{H} 164(\mathrm{~A})$ & -1.084 & & & C145(B) & -2.014 & -2.496 & -1.792 \\
\hline M165(A) & -3.743 & -3.731 & -1.342 & H163(B) & & -0.827 & \\
\hline E166(A) & -8.312 & -3.029 & & H164(B) & & -0.324 & \\
\hline L167(A) & -2.472 & & & M165(B) & -1.598 & -0.942 & -0.911 \\
\hline P168(A) & -1.663 & & & E166(B) & -4.084 & -0.96 & \\
\hline F185(A) & -0.972 & & & L167(B) & & & \\
\hline V186(A) & -1.936 & & & P168(B) & & & \\
\hline D187(A) & -0.598 & -0.766 & & H172(B) & & & -1.363 \\
\hline
\end{tabular}




\begin{tabular}{|lllll|}
\hline R188(A) & -1.366 & -0.858 & D187(B) \\
\hline Q189(A) & -3.45 & -2.536 & -0.808 & R188(B) \\
\hline T190(A) & -0.963 & & Q189(B) & -2.066 \\
\hline Q192(A) & & 213(A) & -0.584 \\
\hline SER1(B) & -1.409 & N214(A) & -0.968 \\
\hline Cys300(B) & -1.108 & G302(A) & -0.635 \\
\hline Ser301(B) & -1.367 & V303(A) & -2.404 \\
\hline
\end{tabular}

Sub1 and sub2 denote interactions between ligand and subunits 1 or 2 of dimeric SARS-CoV $3 \mathrm{CL}^{\text {pro }}$. (A) and $(\mathrm{B})$ denote chain $\mathrm{A}$ and $\mathrm{B}$.

\section{Figures}


$\mathbf{A}$

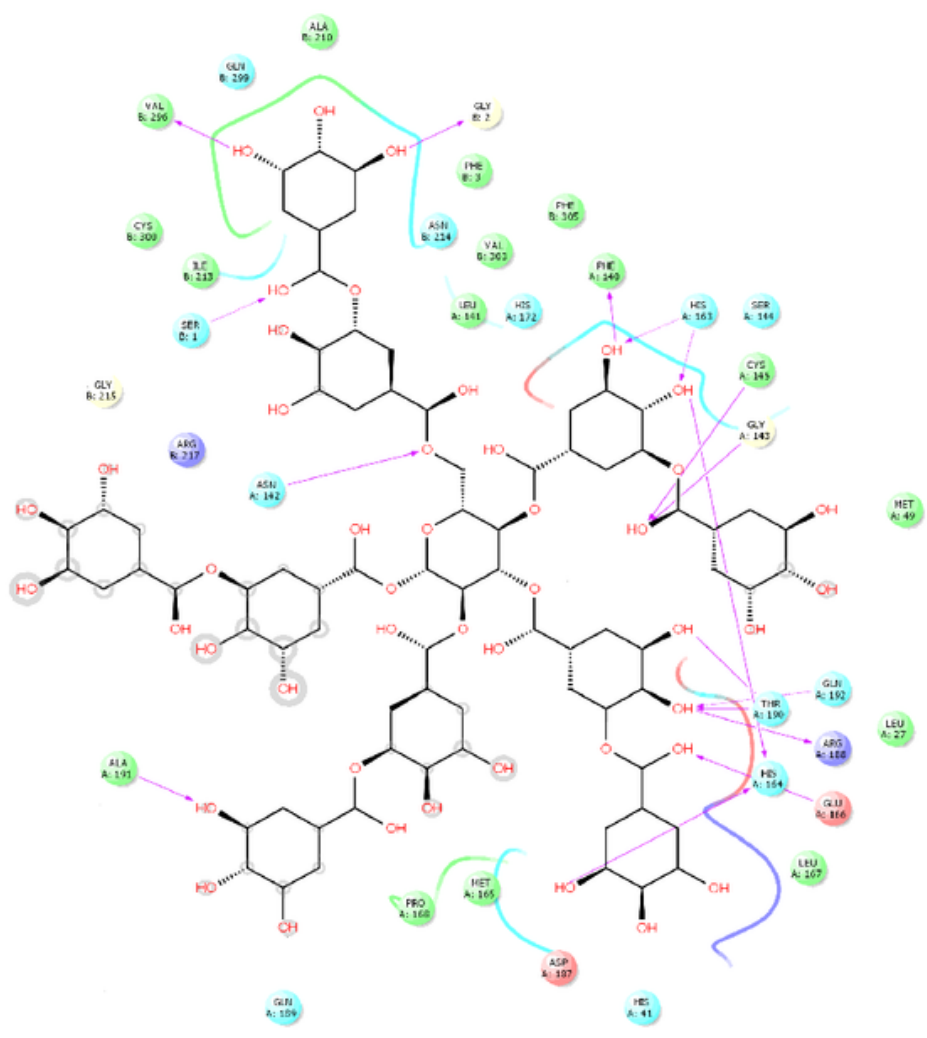

$\mathbf{B}$

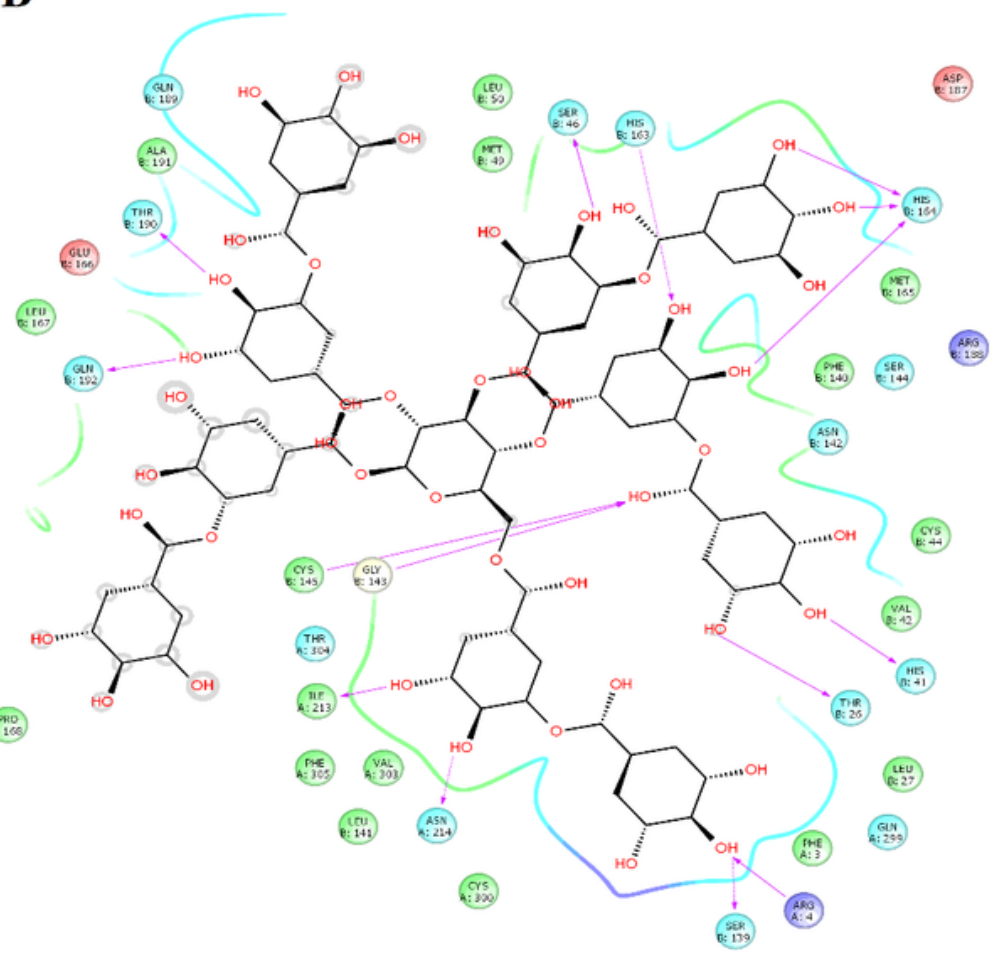

\section{Figure 1}

Interactions of the complex between tannic acid and 3CLpro of SARS-CoV-2. Map of interaction of tannic acid at subunit 1 (A) and subunit 2 (B). The figure was constructed with Maestro Schrödinger version 10.5 . 

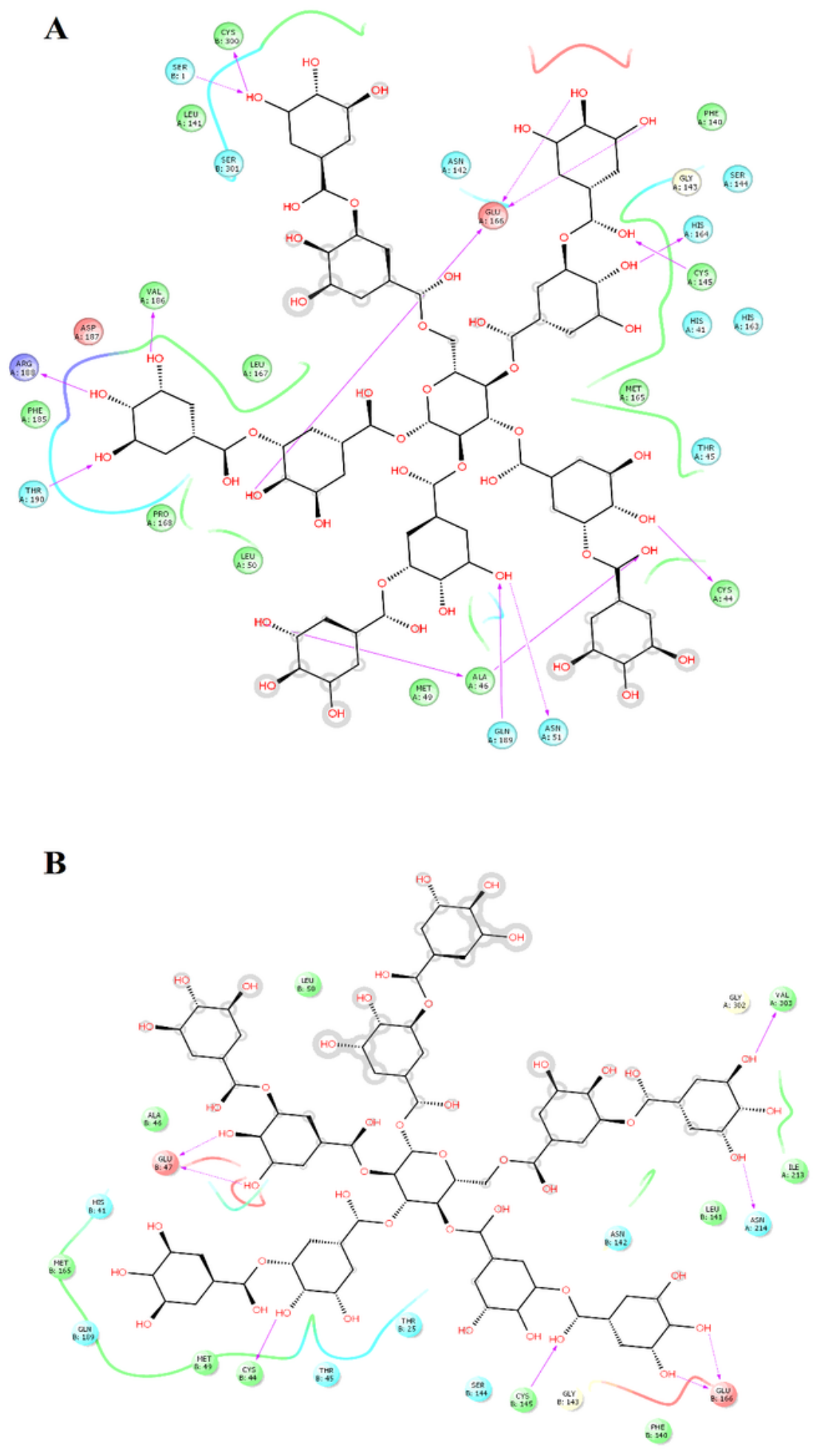

Figure 2

Interactions of the complex between tannic acid and 3CLpro of SARS-CoV. Map of interaction of tannic acid at subunit 1 (A) and subunit 2 (B) of SARS-CoV. 
A

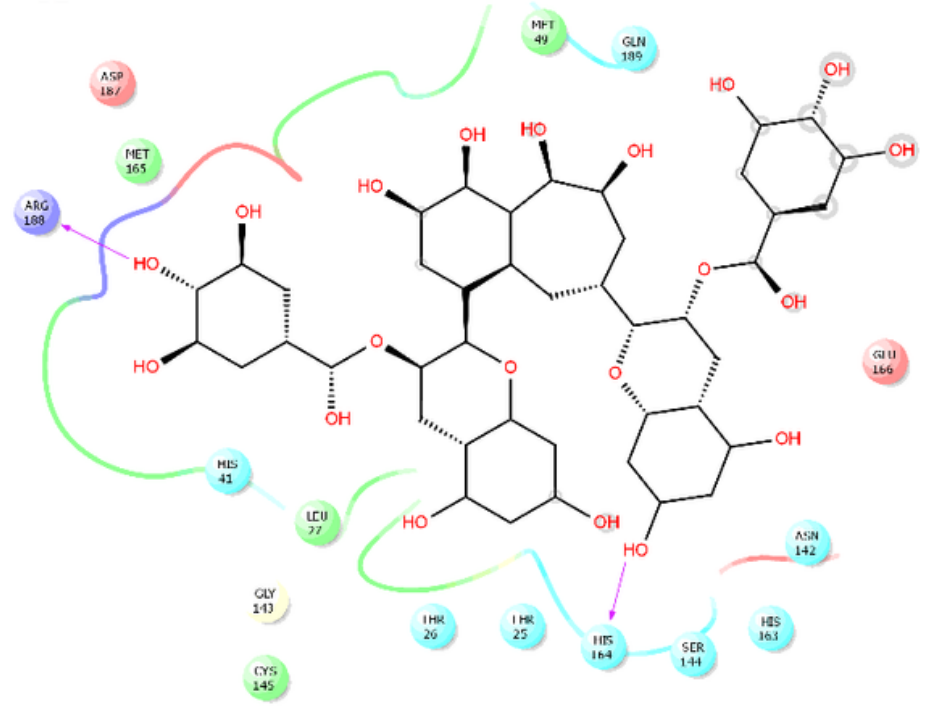

B

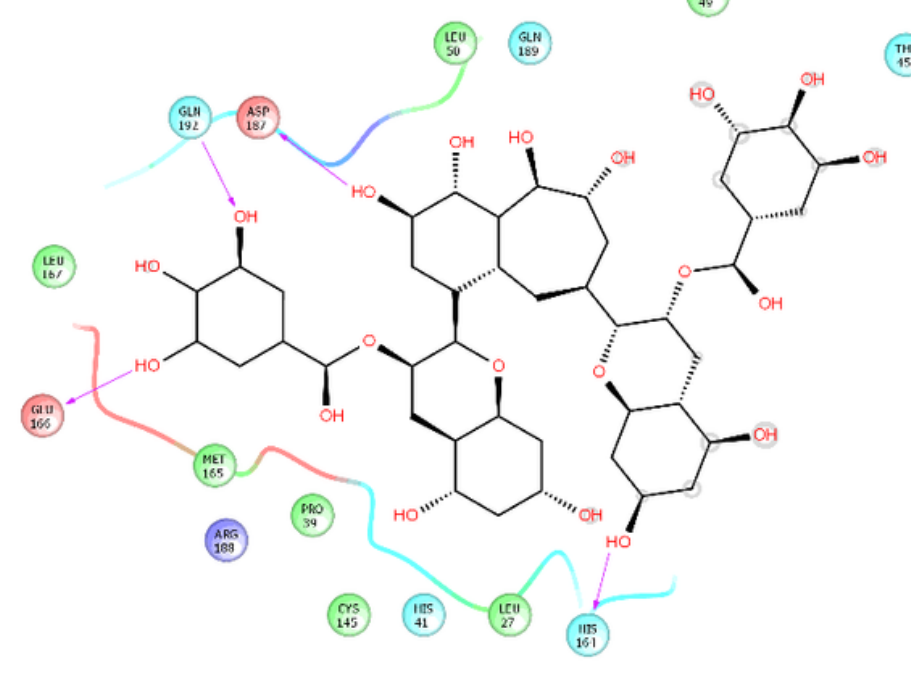

(1:is)
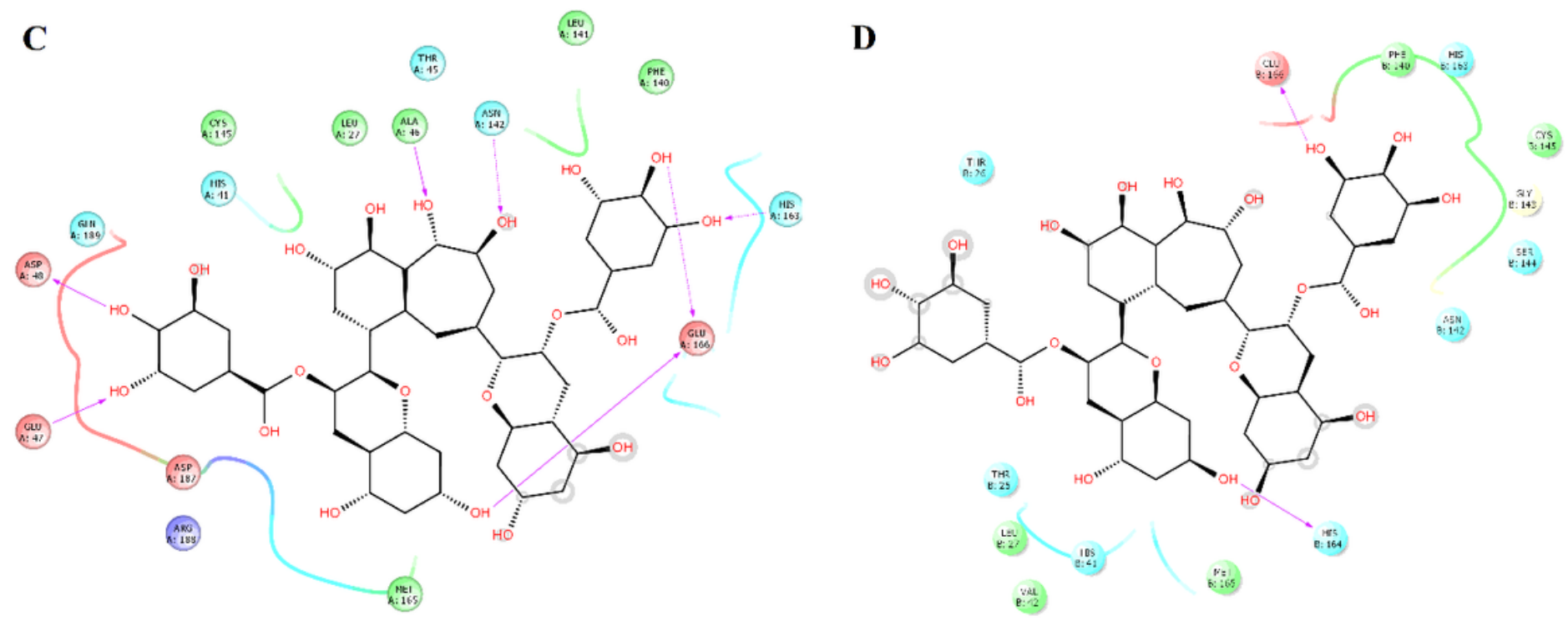

Figure 3

Interactions of the complex between TF3 and 3CLpro of SARS-CoV-2 and SARS-CoV. Map of interaction of TF3 at subunit 1 (A) and subunit 2 (B) of SARS-CoV-2. TF3 at subunit 1(C) and 2 (D) of SARS-CoV. 
A

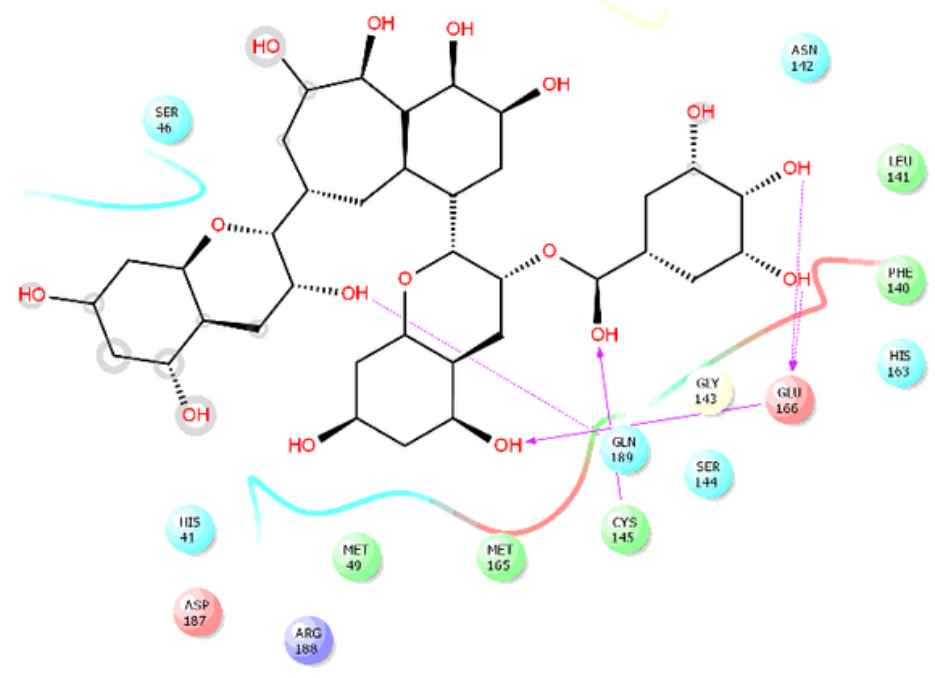

C

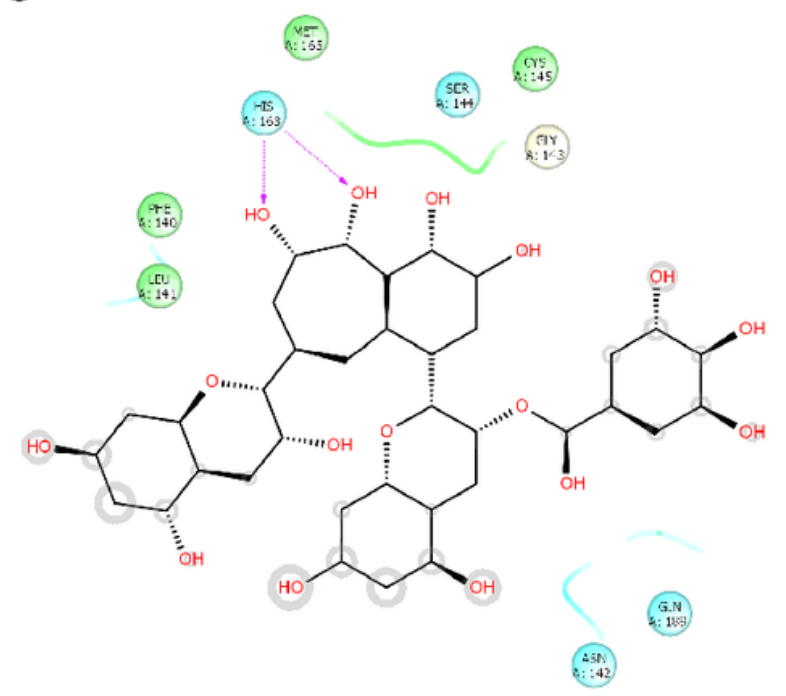

(1:i:

(19:

(1:i1)
B

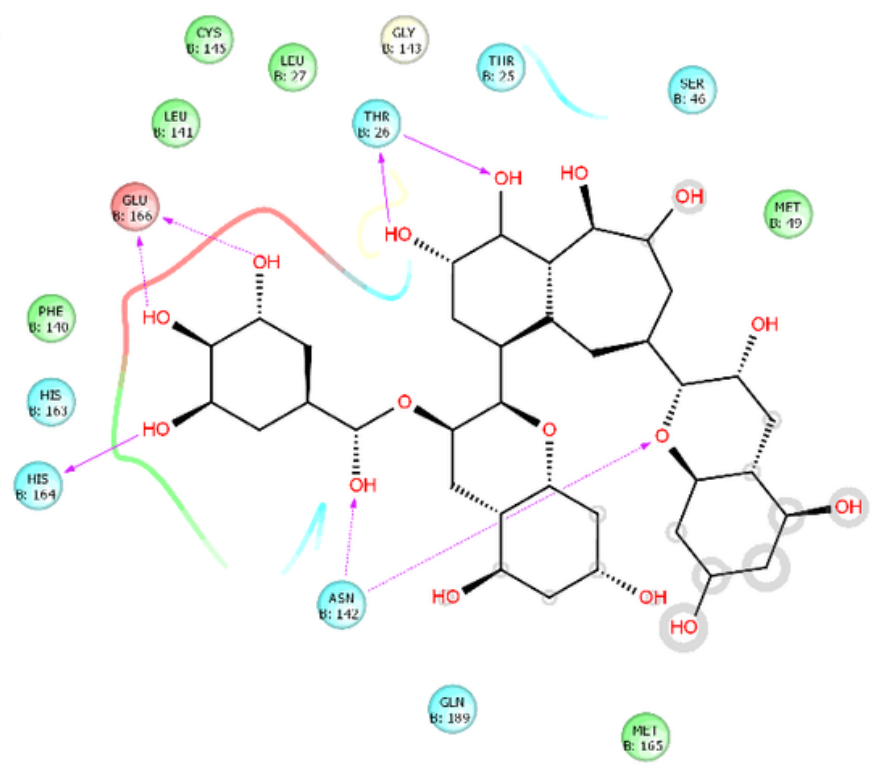

D

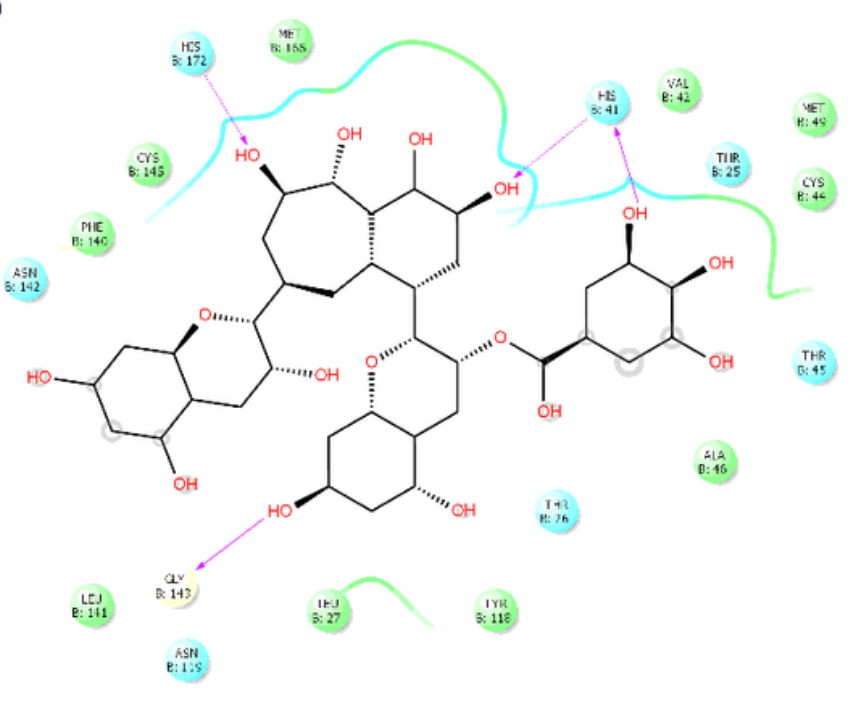

Figure 4

Interactions of the complex between TF2B and 3CLpro of SARS-CoV-2 and SARS-CoV. Map of interaction of TF2B at subunit 1 (A) and subunit 2 (B) of SARS-CoV-2. TF2B at subunit 1(C) and 2 (D) of SARS-CoV.

\section{Supplementary Files}

This is a list of supplementary files associated with this preprint. Click to download.

- supplementarymaterial.pdf 